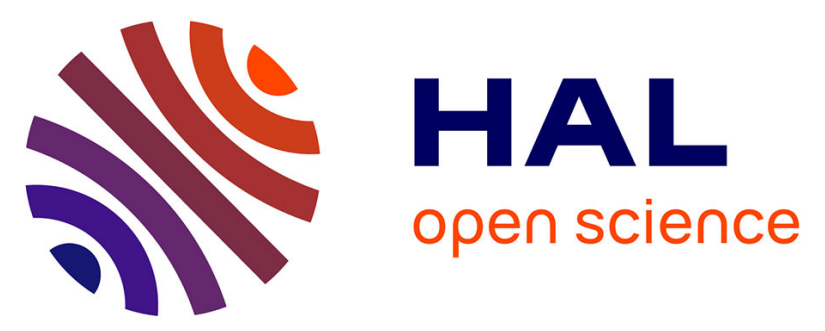

\title{
Carbonation of model cement pastes: The mineralogical origin of microstructural changes and shrinkage
}

\author{
E. Kangni-Foli, Stéphane Poyet, P. Le Bescop, T. Charpentier, F. \\ Bernachy-Barbé, A. Dauzères, E. L'Hôpital, Jean-Baptiste D'espinose de \\ Lacaillerie
}

\section{- To cite this version:}

E. Kangni-Foli, Stéphane Poyet, P. Le Bescop, T. Charpentier, F. Bernachy-Barbé, et al.. Carbonation of model cement pastes: The mineralogical origin of microstructural changes and shrinkage. Cement and Concrete Research, 2021, 144, pp.106446. 10.1016/j.cemconres.2021.106446 . hal-03194818

\section{HAL Id: hal-03194818 \\ https://hal.science/hal-03194818}

Submitted on 9 Apr 2021

HAL is a multi-disciplinary open access archive for the deposit and dissemination of scientific research documents, whether they are published or not. The documents may come from teaching and research institutions in France or abroad, or from public or private research centers.
L'archive ouverte pluridisciplinaire HAL, est destinée au dépôt et à la diffusion de documents scientifiques de niveau recherche, publiés ou non, émanant des établissements d'enseignement et de recherche français ou étrangers, des laboratoires publics ou privés.

\section{(1) (1) $\$$}

Distributed under a Creative Commons Attribution - NonCommercial - NoDerivatives| 4.0 


\title{
Carbonation of model cement pastes: The mineralogical origin of microstructural changes and shrinkage
}

\author{
E. Kangni-Foli ${ }^{\text {a,b,c }}$, S. Poyet ${ }^{\text {c, }}$, P. Le Bescop ${ }^{c}$, T. Charpentier ${ }^{\text {d }}$, F. Bernachy-Barbé ${ }^{c}$, \\ A. Dauzères ${ }^{a}$, E. L'Hôpital ${ }^{a}$, J.-B. d'Espinose de Lacaillerie ${ }^{b}$ \\ ${ }^{a}$ IRSN, Institute of Radiation Protection and Nuclear Safety, PSE-ENV/SEDRE/LETIS, BP 17, F-92262 Fontenay aux Roses, France \\ ${ }^{\mathrm{b}}$ Soft Matter Science and Engineering, UMR CNRS 7615, ESPCI Paris, Université PSL, 10 rue Vauquelin, 75005 Paris, France \\ ${ }^{\mathrm{c}}$ Université Paris-Saclay, CEA, Service d'Etude du Comportement des Radionucléides, 91191 Gif-sur-Yvette, France \\ ${ }^{\mathrm{d}}$ NIMBE, CEA, CNRS, Université Paris-Saclay, CEA Saclay, F-91191 Gif-sur-Yvette cedex, France
}

\section{A R T I C L E I N F O}

\section{Keywords:}

Cement

Carbonation

C-S-H

Shrinkage

Microstructure

\begin{abstract}
A B S T R A C T
This study explored the reactive processes of atmospheric carbonation and the consequences with respect to cementitious materials. Two model pastes were used: hydrated $\mathrm{C}_{3} \mathrm{~S}$ (including C-S-H and portlandite) and a paste prepared by hydrating a blend of $\mathrm{C}_{3} \mathrm{~S}$ and nanosilica (including $\mathrm{C}-\mathrm{S}-\mathrm{H}$ only). The two pastes were carbonated under accelerated conditions in the laboratory. The resulting mineralogical assemblage was examined using $\mathrm{X}$ ray diffraction, thermogravimetric analysis and nuclear magnetic resonance. The microstructural changes were studied by X-ray tomography and porosimetry, and their macroscopic impacts were evaluated through gas diffusion and shrinkage measurements. The use of model pastes allowed for the evaluation of the change in solid volume induced by the carbonation of C-S-H. C-S-H decalcification and subsequent silica chain polymerisation were found responsible for carbonation shrinkage (and potentially cracking). Finally, the results highlight the protective role of portlandite: portlandite helped in limiting C-S-H decalcification and then reducing carbonation shrinkage and cracking.
\end{abstract}

\section{Introduction}

Atmospheric carbonation of cementitious materials refers to the reaction between atmospheric carbon dioxide $\left(\mathrm{CO}_{2}\right)$ and the calcium ions $\left(\mathrm{Ca}^{2+}\right)$ that are present in the pore solution [1]. This reaction leads to the precipitation of calcium carbonate [2,3] at the expense of Ca-bearing hydrates; among them, calcium hydroxide (portlandite, $\mathrm{CH}$ ) and calcium silicate hydrates (C-S-H). The main consequence of carbonation is a strong $\mathrm{pH}$ reduction of the pore solution that can initiate active corrosion of steel reinforcement [4,5]. Atmospheric carbonation has long been studied, and its mechanisms are now well-known and described. This has made it possible to propose models to describe the carbonation of concretes [6-11].

Nonetheless, the available models and the subsequent descriptions of carbonation are far from being fully satisfactory and some issues remain. Although portlandite and calcium carbonate can be easily quantified using thermogravimetric analysis (TGA), the other Ca-bearing hydrates (C-S-H and sulfo-aluminates for instance) cannot. It is then difficult to obtain comprehensive and reliable experimental results, such as mineralogical profiles that are needed for validating geochemical simulations [12].

Similarly, the link between the changes in chemistry, microstructure and macroscopic properties has not been clearly described until now. For instance, the change in total porosity induced by carbonation remains uncertain: it is trivial when considering portlandite carbonation, but the case of C-S-H is more complex. This is mainly due to the fact that the C-S-H molar volume is still uncertain and probably variable: different values ranging from 68 to $126 \mathrm{~cm}^{3} / \mathrm{mol}$ have been used so far for high C/S C-S-H (ca. 1.5-1.7) [13-25]. Furthermore, the molar volume of the end-product of C-S-H carbonation - silica gel - also remains uncertain with values ranging from 12 to $30 \mathrm{~cm}^{3} / \mathrm{mol}$ [26-28].

Another point of interest is carbonation shrinkage [29-33] and the cracking that can result from it [34-37]. Carbonation-induced cracking was shown to depend on, among other things, the mineralogical composition (mainly portlandite and C-S-H contents) of the considered material [35]: blended cement specimens (such as CEM III, CEM V and low-alkalinity blends) cracked upon carbonation, which led to a strong increase in their transport properties whereas, on the contrary, it 
decreased in Portland cement specimens because they remained almost crack-free. Because of the cracking, carbonation blurs the link between microstructure and transport as it is currently accepted: the finer the pore-size distribution, the lower the transport properties [38-41].

In view of those considerations, it is the objective of this study to use two model pastes [42], the mineralogical composition of which was designed to be able to study the impact of carbonation on C-S-H alone, independently of portlandite, and to obtain quantitative data. The changes in mineralogy and microstructure were probed concurrently to allow for investigation of the consequences of carbonation in terms of mineralogical volume changes and macroscopic shrinkage. The results also highlight the central role of portlandite: the presence of portlandite did reduce the carbonation rate, but it also helped in mitigating the consequences of carbonation (shrinkage and cracking).

\section{Materials}

Two model pastes were used in this study: a tricalcium silicate $\left(\mathrm{C}_{3} \mathrm{~S}\right)$ paste $(\mathrm{C} / \mathrm{S}=3.0)$, namely a matrix of $\mathrm{C}-\mathrm{S}-\mathrm{H}$ embedding portlandite crystals and another one composed of C-S-H only with a target $\mathrm{C} / \mathrm{S}$ ratio of 1.4. Note that the latter is more or less the highest value that can be obtained without precipitating portlandite [43-49]. The former is hereafter referred to as the $\mathrm{C}_{3} \mathrm{~S}$ paste and the latter as the C-S-H paste. The C-S-H paste was prepared by mixing triclinic $\mathrm{C}_{3} \mathrm{~S}$ with the stoichiometric amount of nanosilica. The triclinic $\mathrm{C}_{3} \mathrm{~S}$ was provided by Mineral Research Processing (Meyzieu, France); and it had a specific surface area of $4600 \mathrm{~cm}^{2} / \mathrm{g}$. The nanosilica was provided by BASF (Rheomac AS150) as a colloidal suspension in water (50\% in weight); the nanosilica had a median diameter equal to $100 \mathrm{~nm}$. The main goal of the design was to obtain pourable pastes. A water-to-binder ratio of 0.50 was enough to ensure workability of the $\mathrm{C}_{3} \mathrm{~S}$ paste (Table 1 ). However, due to the high water demand of the nanosilica, the $\mathrm{w} / \mathrm{b}$ ratio of the C-S$\mathrm{H}$ paste had to be significantly increased in order to maintain workability [50,51]. It was then decided to use a commercial superplasticizer (Masterglenium Sky 537 from BASF) to limit the increase in $\mathrm{w} / \mathrm{b}$ resulting in the composition reported in Table 1 . Further details on the design, batching and main properties of the pastes are provided elsewhere [42].

For each paste, two kinds of specimens were produced using PTFE cylindrical moulds $(\varnothing=14 \mathrm{~mm}, \mathrm{H}=90 \mathrm{~mm}$; and $\varnothing=30 \mathrm{~mm}, \mathrm{H}=120$ $\mathrm{mm}$ ). The latter were designed to measure length variations and, more specifically, the carbonation shrinkage (see Section 3.5). After casting, all the samples were kept for one month in their sealed moulds before they were unmoulded and then kept for two additional months in airtight containers immersed in a specific solution to prevent leaching (deionised water and portlandite in excess for the $\mathrm{C}_{3} \mathrm{~S}$ paste and deionised water with crushed $\mathrm{C}-\mathrm{S}-\mathrm{H}$ samples for the C-S-H paste).

Some of the main properties of the two pastes are listed in Table 2, and more information can be found in our preceding work [42]. The $\mathrm{C}_{3} \mathrm{~S}$ paste displayed portlandite and C-S-H contents comparable to those of a fully hydrated OPC paste, despite a very small residual signal of anhydrous tricalcium silicate detected by X-ray diffraction (XRD) [42]. The C-S-H paste showed a higher porosity and lower saturated density compared with those of the $\mathrm{C}_{3} \mathrm{~S}$ paste. This is the direct result of the

Table 1

Composition of the model pastes for $1 \mathrm{~L}$ of paste.

\begin{tabular}{lcll}
\hline & $\mathrm{C}_{3} \mathrm{~S}$ paste $(\mathrm{C} / \mathrm{S}=3.0)$ & C-S-H paste $(\mathrm{C} / \mathrm{S}=1.4)$ & Unit \\
\hline $\mathrm{C}_{3} \mathrm{~S}(\mathrm{~g})$ & 1218.8 & 791.7 & $\mathrm{~g}$ \\
Nanosilica $(\mathrm{g})$ & 0.0 & 237.9 & $\mathrm{~g}$ \\
Water $(\mathrm{g})$ & 609.4 & 617.8 & $\mathrm{~g}$ \\
w/b ratio & 0.50 & $0.63^{\mathrm{a}}$ & - \\
Superplasticiser & 0.0 & $31.1^{\mathrm{b}}$ & $\mathrm{g}$ \\
Batching duration & 5 & 8 & $\mathrm{~min}$ \\
\hline
\end{tabular}

a Includes the water introduced by the superplasticiser.

${ }^{b}$ Represents $3 \%$ of the binder weight $\left(\mathrm{C}_{3} \mathrm{~S}+\right.$ nanosilica).
Table 2

Composition and main properties of the two model pastes [42].

\begin{tabular}{|c|c|c|c|}
\hline & $\begin{array}{l}\mathrm{C}_{3} \mathrm{~S} \text { paste }(\mathrm{C} / \mathrm{S}= \\
3.0)\end{array}$ & $\begin{array}{l}\mathrm{C}-\mathrm{S}-\mathrm{H} \text { paste }(\mathrm{C} / \mathrm{S}= \\
1.4)\end{array}$ & Unit \\
\hline $\mathrm{C} / \mathrm{S}$ of the C-S-H & $1.7^{\mathrm{a}}$ & $1.4^{\mathrm{b}}$ & - \\
\hline $\begin{array}{l}\text { Porosity (drying at } \\
\left.80^{\circ} \mathrm{C}\right)^{\mathrm{c}}\end{array}$ & $38 \%$ & $52 \%$ & - \\
\hline $\begin{array}{l}\text { Porosity (drying at } \\
\left.105^{\circ} \mathrm{C}\right)^{\mathrm{c}}\end{array}$ & $41 \%$ & $56 \%$ & - \\
\hline Saturated density & 1.89 & 1.76 & $\mathrm{~g} / \mathrm{cm}^{3}$ \\
\hline Amount of C-S-H & 5.6 & 7.0 & $\begin{array}{l}\mathrm{mol} / \mathrm{L} \text { of } \\
\text { paste }\end{array}$ \\
\hline Amount of $\mathrm{CH}^{\mathrm{e}}$ & 7.3 & 0.0 & $\begin{array}{l}\text { mol/L of } \\
\text { paste }\end{array}$ \\
\hline Young's modulus $\mathrm{E}^{\mathrm{f}}$ & $15 \pm 1$ & $10 \pm 1$ & $\mathrm{GPa}$ \\
\hline $\begin{array}{l}\text { a Assumed value b } \\
\text { b Measured using } \\
\text { c Drying at } 105{ }^{\circ} \\
\text { drying at } 80{ }^{\circ} \mathrm{C} \text { was } \\
\text { d Using the approa } \\
\text { e Using TGA and tl } \\
\text { f Using the impuls }\end{array}$ & $\begin{array}{l}\text { t verified. } \\
\text { EDX. } \\
\text { s used to enable } \\
\text { idered to be less } \\
\text { f Olson \& Jennin } \\
\text { ngential method } \\
\text { itation technique }\end{array}$ & $\begin{array}{l}\text { mparison with the } \\
\text { sressive and more } r \\
\text { [13]. } \\
\text { 2]. } \\
\text { SrindoSonic }(\mathbb{R}) \text {. }\end{array}$ & $\begin{array}{l}\text { iterature, but } \\
\text { alistic. }\end{array}$ \\
\hline
\end{tabular}

higher $\mathrm{w} / \mathrm{b}$ ratio required to maintain workability of the fresh paste. The difference in water content resulted in a different microstructure for the two pastes (see Section 4.2).

\section{Methods}

\subsection{Accelerated carbonation}

After curing and prior to carbonation, all the samples were introduced into $\mathrm{C}_{2}$-free glovebox and kept in a desiccator (equipped with fans to avoid moisture gradients), in which the $\mathrm{RH}$ was maintained at $55 \%$ at ambient temperature using a saturated solution of $\mathrm{Mg}\left(\mathrm{NO}_{3}\right)_{2}$ [53]. After 170 days of drying (when the mass variation became constant), the specimens were covered with adhesive aluminium foils to ensure unidirectional carbonation. They were then introduced into the carbonation chamber [54] where they were carbonated at $25{ }^{\circ} \mathrm{C} \pm$ $0.2{ }^{\circ} \mathrm{C}, 55 \% \mathrm{RH} \pm 1 \%$ and $3.0 \% \mathrm{CO}_{2} \pm 0.2 \%$. This $\mathrm{CO}_{2}$ content was selected because it has been proven that accelerated carbonation at $3 \%$ $\mathrm{CO}_{2}$ gave results that were similar to those of natural carbonation in terms of mineralogy, microstructure and cracking [55]. Accelerated carbonation was monitored for nearly one year (326 and 316 days for the $\mathrm{C}_{3} \mathrm{~S}$ and $\mathrm{C}-\mathrm{S}-\mathrm{H}$ pastes, respectively).

\subsection{Mineralogy}

X-ray diffraction (XRD) was used to identify the change in mineralogy induced by carbonation. The cylinders were cut orthogonally to the carbonation direction and the diffractograms were acquired on the (polished) solid surface [56], using a PANalytical X'Pert diffractometer equipped with a X'celerator detector using Cu-K $\alpha$ radiation $(\lambda=1.54 \AA)$. The diffractograms were collected at ambient temperature from $5^{\circ}$ to $60^{\circ}$ in $2 \theta$ with a step size of $0.017^{\circ}$ and a dwell time of $40 \mathrm{~s}$ resulting in a total test time of about $20 \mathrm{~min}$. The diffractograms were compared to the following ICDD reference files: portlandite (CH), 44-1481; vaterite, 0174-1487; calcite, 05-0586; aragonite, 70-9854; and triclinic tricalcium silicate $\left(C_{3} S\right)$, 31-0301. Rietveld analyses were run for quantification purposes; mainly to quantify the relative amounts of the three $\mathrm{CaCO}_{3}$ polymorphs (cf. Fig. 6). In hydrated cement pastes, quantitative XRD analysis is known to be difficult due to the presence of poorly crystalline C-S-H [57]. In the carbonated materials, the presence of amorphous silica gel and amorphous calcium carbonate (that cannot be easily accounted for) increased the difficulty and the corresponding uncertainty. Rietveld analyses were thus not expected to give an accurate quantification of the different phases in presence, rather a rough 
estimate. Here we made use of the C-S-H models proposed by Richardson [58] to describe the C-S-H contribution to the experimental diffractogram. Practically speaking, all the sixteen the C-S-H models proposed by Richardson (in addition to portlandite, calcite, aragonite and vaterite) were introduced into the Rietveld fitting tool of the Malvern Panalytical Highscore Plus software that automatically adjusted the mass fraction of each component to fit the experimental diffractogram.

Thermogravimetric analysis (TGA) was performed using a Netzsch STA 409 PC Luxx apparatus. Analyses were run using $120 \mathrm{mg}$ of powdered sample under a constant $\mathrm{N}_{2}$ flowrate $(80 \mathrm{~mL} / \mathrm{min})$. The weight losses were recorded from $25^{\circ} \mathrm{C}$ to $1150{ }^{\circ} \mathrm{C}$ with a heating rate of $10{ }^{\circ} \mathrm{C} / \mathrm{min}$ [59]. The quantification of the amounts of portlandite and calcium carbonate was performed using the tangential method [52], considering the mass loss between $400{ }^{\circ} \mathrm{C}$ and $600^{\circ} \mathrm{C}$ for portlandite and between $600{ }^{\circ} \mathrm{C}$ and $900{ }^{\circ} \mathrm{C}$ for calcium carbonates.

A single pulse ${ }^{29} \mathrm{Si}$ magic angle spinning nuclear magnetic resonance $\left({ }^{29} \mathrm{Si}\right.$ MAS NMR) experiment was performed on a Bruker Avance III 500 spectrometer operating at the Larmor frequency resonance of $99.3 \mathrm{MHz}$. The operational conditions were set to $\pi / 2$ pulses of $3.5 \mu$ s recycle delays of $20 \mathrm{~s}$, spinning in a $7 \mathrm{~mm}$ zirconia rotor at $5.5 \mathrm{kHz}$, and a minimum of 4000 scans for each spectrum. Tetramethylsilane was used as an external standard $(0 \mathrm{ppm})$ to report the chemical shifts. The ${ }^{29} \mathrm{Si} \mathrm{NMR}$ spectra gave an insight into the C-S-H structure. The silicate environments are specified as $\mathrm{Q}^{\mathrm{n}}$ with $0 \leq n \leq 4$ where $n$ stands for the number of silicates connected to a tetrahedral silicate denoted by Q [60-62]. Similar to tobermorite - the C-S-H natural crystalline analogous [58,63-65] - three main environments can be found in C-S-H characterised by $n$ values between 0 and $2[43,66]$. The first corresponds to the silicate end chain unit, namely $\mathrm{Q}^{1}$, with resonance of about $-80 \mathrm{ppm}$. The other two are $\mathrm{Q}^{2}$ sites, which include $\mathrm{Q}^{2 \mathrm{~b}}$ and $\mathrm{Q}^{2 \mathrm{p}}$ environment, that are associated to the bridging (superscript $b$ ) tetrahedral silicate with resonance around $-83 \mathrm{ppm}$ and the pairing (superscript p) silicates around $-85 \mathrm{ppm}$, respectively. Those environments are the three units of the tobermorite dreierketten structure $[64,67]$. Silicate in C-S-H forms chains with variable lengths, high calcium content in C-S-H leading to a higher proportion of low coordination silicates $\mathrm{Q}^{1}$ [58], i.e. C-S-Hs with shorter silicate chains. The ${ }^{29} \mathrm{Si}$ MAS NMR results were processed using the latest version of an in-house software developed previously [68]. The spectra were fitted using Gaussian-Lorentzian line shapes with chemical shifts and parameters included in the Appendix.

\subsection{Microstructure}

X-ray micro-Computed Tomographic (X- $\mu \mathrm{CT})$ projections were acquired using a Bruker SkyScan 1173 device equipped with a flat panel detector $(2240 \times 2240$ pixels $)$ using the following tube operating conditions: $115-130 \mathrm{kV}$ and $61-69 \mu \mathrm{A}$. A full $360^{\circ}$ set of projections was obtained with a rotational step of $0.3^{\circ}$, exposure time of $1100 \mathrm{~ms}$, a frame averaging from 8 to 10 , and images with a pixel size of $16.8 \mu \mathrm{m}$. A grey level profile along the vertical axis was plotted and averaged over "slices" of two voxels in thickness. The carbonation front was obtained by applying a logistic function $(E-1)$ to the sigmoid part of the curve obtained by plotting the grey level with respect to the position (the slices). The carbonation front was delimited as follows: Its beginning was defined as the position associated with $104 \%$ of the lower grey value $\left(L_{\min }\right)$ and its end by the position associated with $96 \%$ of the highest value $\left(L_{\max }\right)$. In other words, the carbonation front was located between the position values associated with $0.96 L_{\max }$ and $1.04 L_{\min }$ (see Fig. 1).

$L(z)=L_{\min }+\frac{\left(L_{\max }-L_{\min }\right)}{1+\exp \left[A\left(z_{0}-z\right)\right]}$

where $L(z)$ is the grey level for the position $z$ in the sample; $L_{\min }$ and $L_{\max }$ minimal and maximal grey levels in the profile respectively; $A$ positive constant and $z_{0}$ position of the sigmoid midpoint.

The position of the carbonation front was also characterised using

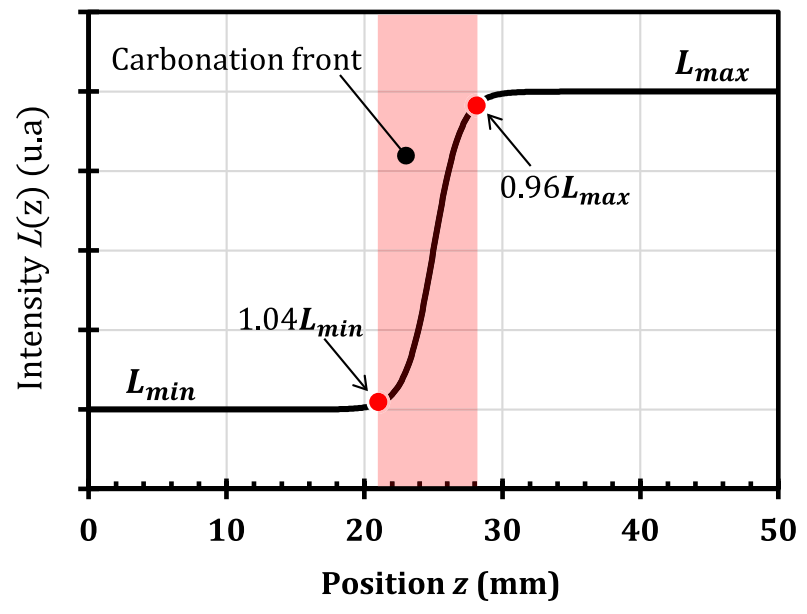

Fig. 1. Illustration of the evaluation of the carbonation front position using equation equation (1) $\left(L_{\min }=1000 ; L_{\max }=5000 ; A=1 ; z_{0}=25 \mathrm{~mm}\right)$.

phenolphthalein: samples were cut along their vertical axis and the fresh surfaces were sprayed with phenolphthalein. The carbonated parts (with $\mathrm{pH}$ value lower than 9.0) remained colourless, whereas non-carbonated parts (with higher $\mathrm{pH}$ values) turned purple.

Density and total porosity of the pastes were measured using the buoyancy method using disks $(\varnothing=30.0 \mathrm{~mm}, \mathrm{H}=8 \mathrm{~mm})$ that were cut from the central part of larger cylinders $(\varnothing=30 \mathrm{~mm}, \mathrm{H}=120 \mathrm{~mm})$. Prior to the tests, the samples were re-saturated under vacuum [69]. The mass loss associated with an oven drying at $80^{\circ} \mathrm{C}$ and $105^{\circ} \mathrm{C}$ enabled the total (accessible) porosity of the samples to be estimated.

Some samples were crushed in centimetric pieces, immersed in liquid nitrogen and then freeze-dried for $24 \mathrm{~h}$ before they were tested using mercury intrusion porosimetry (MIP). Four samples were used for each analysis. A Micromeritics Autopore IV device was used at a maximal pressure of $414 \mathrm{MPa}$ (corresponding to pores of $3 \mathrm{~nm}$ in diameter).

\subsection{Gas diffusion}

The gas diffusion coefficient of the carbonated pastes was measured using the through-diffusion method [70,71]. The tests were conducted using three disks $(\varnothing=30.0 \mathrm{~mm}, \mathrm{H}=8 \mathrm{~mm}$ ) each time. The samples to be tested were placed between two chambers; the first filled with synthetic air $-20 \%$ of oxygen $\left(\mathrm{O}_{2}\right)$ and $80 \%$ of nitrogen $\left(\mathrm{N}_{2}\right)$ - and the second one filled with nitrogen $\left(\mathrm{N}_{2}\right)$ (Fig. 2). Note that the conditions in the two chambers were the same (ambient temperature at atmospheric pressure and $55 \% \mathrm{RH}$ ). Also note that, due to the presence of water vapour, the gas concentration within the two chambers was slightly lower than $100 \%$, but this was not accounted for in the assessment of the gas diffusion coefficients.

Prior to the tests, the carbonated disks ( $\varnothing 30 \times 8 \mathrm{~mm}$ ) were first saturated in a desiccator under water with a vacuum [69] and then

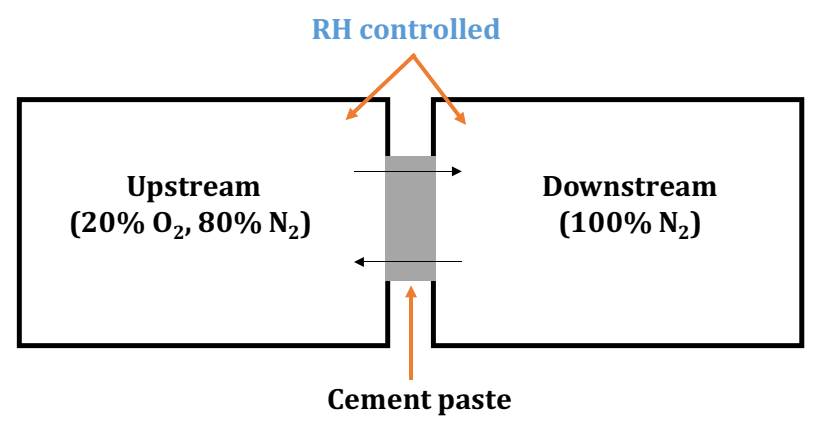

Fig. 2. Principle of the gas diffusion test. 
equilibrated at $55 \% \mathrm{RH}$ and ambient temperature $\left(20^{\circ} \mathrm{C} \pm 2{ }^{\circ} \mathrm{C}\right)$. They were then sealed in position using epoxy adhesive and O-rings to avoid gas leakage during the diffusion test. The respective diffusion of oxygen and nitrogen through the disks was monitored using gas microchromatography, and the resulting diffusion coefficients were evaluated using Fick's 2nd law [72].

In parallel to the direct measurements, the simple model proposed by Papadakis et al. [73,74] was used to assess the diffusion coefficient of $\mathrm{CO}_{2}$ of the two carbonated pastes. This proved to be necessary in some cases because of cracking. The model by Papadakis creates a link between the carbonation depth $x_{c}$ and the square root of time $t$ :

$\mathrm{x}_{\mathrm{c}}(\mathrm{t})=\mathrm{k} \sqrt{\mathrm{t}}$ with $\mathrm{k}=\sqrt{\frac{2 \mathrm{D}_{\mathrm{CO}_{2}}^{\mathrm{c}}\left[\mathrm{CO}_{2}\right]}{[\mathrm{Ca}]_{\text {carbo }}}}$

where $k$ is the carbonation rate; $D_{\mathrm{CO}_{2}}{ }^{c}$ is the diffusion coefficient value for $\mathrm{CO}_{2}$ through the carbonated material; $\left[\mathrm{CO}_{2}\right]$ is the concentration of $\mathrm{CO}_{2}$ and $[\mathrm{Ca}]_{\text {carbo }}$ is the concentration of $\mathrm{Ca}$ that can be involved in the carbonation process. Consequently, the value of the $\mathrm{CO}_{2}$ diffusion coefficient $D_{\mathrm{CO}_{2}}{ }^{c}$ can be estimated if the carbonation rate $k$ is measured experimentally:

$D_{\mathrm{CO}_{2}}^{c}=k^{2}\left(\frac{[\mathrm{Ca}]_{\text {carbo }}}{2\left[\mathrm{CO}_{2}\right]}\right)$

More details are provided in the Results section.

\subsection{Shrinkage measurement}

Two of the smaller cylinders $(\varnothing=14 \mathrm{~mm}$ and $\mathrm{H}=80 \mathrm{~mm}$ ) were first re-saturated under vacuum [69] before they were introduced in a climatic chamber where they were subjected to drying at $25{ }^{\circ} \mathrm{C}$ and $55 \%$ $\mathrm{RH}$ (note that the specimens were not protected against the $\mathrm{CO}_{2}$ present in the atmosphere during that phase). After 195 days of drying, they were introduced into the accelerated carbonation chamber where they were subjected to $3 \% \mathrm{CO}_{2}$ at $25{ }^{\circ} \mathrm{C}$ and $55 \% \mathrm{RH}$ for a further 70 days. The change in length was monitored throughout the test using LVDT sensors (Solartron Metrology).

\section{Results}

\subsection{Mineralogy}

Fig. 3 presents some of the diffractograms that were collected in the non-carbonated zone; in the carbonation front and in the carbonated zone of the two pastes. It is evident that the carbonation of the C-S-H paste $(\mathrm{C} / \mathrm{S}=1.4)$ led to the dissolution of the $\mathrm{C}-\mathrm{S}-\mathrm{H}$ and precipitation of calcium carbonate: mainly vaterite and to some extent calcite. This was consistent with the conclusion of Šauman [75] and Auroy et al. [55], which stated that the presence of vaterite was indicative of $\mathrm{C}-\mathrm{S}-\mathrm{H}$ carbonation. In the carbonation front $(40.8 \mathrm{~mm}$ from the surface exposed to $\mathrm{CO}_{2}$ ), the coexistence of calcium carbonate and C-S-H (broad peak at $\left.29^{\circ}[44,76,77]\right)$ could be clearly observed. In the carbonated zone $(15.0 \mathrm{~mm})$, the signal related to C-S-H could no longer be observed, and a very large diffraction band could be observed between $18^{\circ}$ and $27^{\circ}$, which is characteristic of amorphous silica gel (Fig. 4) [78].

The carbonation of the $\mathrm{C}_{3} \mathrm{~S}$ paste was somewhat different: portlandite was never completely dissolved (even in the carbonated zone) and calcite was the main calcium carbonate that was detected. The C-S$\mathrm{H}$ was also not believed to have completely dissolved (even though it was virtually impossible to detect them due to the presence of calcite) because of the absence of the large diffraction band discussed above. This was confirmed using ${ }^{29} \mathrm{Si}$ NMR (Fig. 7).

Fig. 5 presents the mineralogical assemblage obtained using XRD. Note that these results should only be interpreted in a qualitative manner. In the carbonated zone of the C-S-H paste, the C-S-H signal was below the detection limit; the C-S-H were then assumed to be completely and evenly depleted (this was confirmed using ${ }^{29} \mathrm{Si}$ NMR results, Fig. 7). Conversely, portlandite and C-S-H remained in significant amounts in the carbonated zone of the $\mathrm{C}_{3} \mathrm{~S}$ paste. The latter also appeared not to be homogeneous: the first four millimetres were more carbonated than the rest of the carbonated zone in which the amount of calcium carbonate was reduced and the amounts of remaining portlandite and C-S-H
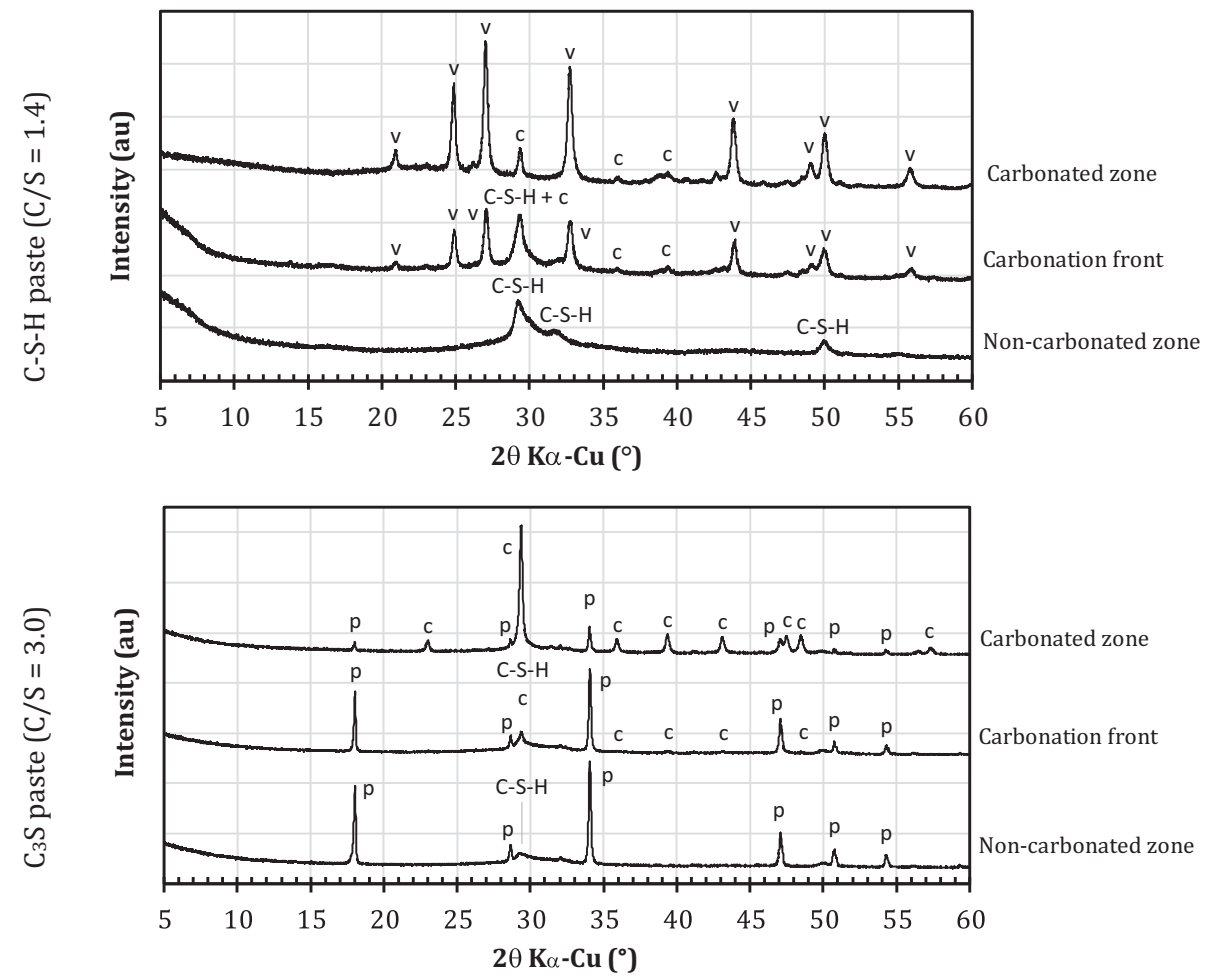

Fig. 3. Diffractograms of the pastes at the end of accelerated carbonation (316 and 326 days for the C-S-H and $\mathrm{C}_{3} \mathrm{~S}$ pastes, respectively). 


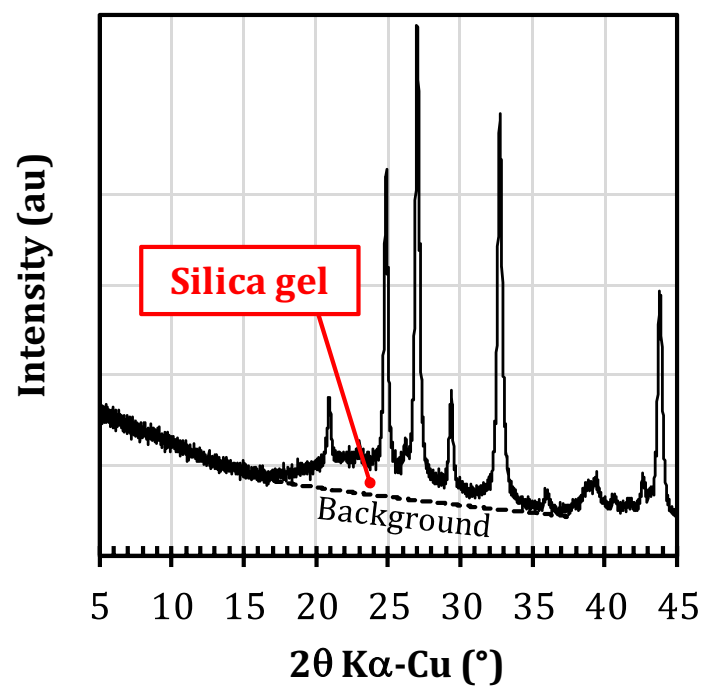

Fig. 4. Evidence of the silica gel presence in the C-S-H paste carbonated zone $(\mathrm{C} / \mathrm{S}=1.4)$.

increased.

Rietveld refinements were conducted to estimate the relative proportions of the three $\mathrm{CaCO}_{3}$ polymorphs (vaterite, aragonite and calcite) in the carbonated zones of the two pastes (Fig. 6). The results confirmed the observations of Fig. 3. Vaterite was the main polymorph that was precipitated in the carbonated zone of the C-S-H paste (around $90 \%$ by weight). It must be noted though that some calcite (less than $10 \%$ ) was detected throughout the carbonated zone as well as aragonite close to the surface exposed to $\mathrm{CO}_{2}$. Conversely, calcite was, by far, the main polymorph that was precipitated in the carbonated zone of the $\mathrm{C}_{3} \mathrm{~S}$ paste. Aragonite and vaterite were only detected close to the surface exposed to $\mathrm{CO}_{2}$. There is no clear explanation for the absence of vaterite in the depth of the carbonated zone of the $\mathrm{C}_{3} \mathrm{~S}$ paste, despite the carbonation of its C-S-H. Nonetheless, phenomena that might explain the observed behaviour include: discrepancies in Ca-supersaturation [79-81] in $\mathrm{pH}$ values [82] (since formation of calcite is reported at saturation index (SI) higher than that of vaterite), the presence of foreign ions (sulfate, silica or magnesium) [83-85], or the effect of the nucleation surface [86] as disturbance of the solvated surface, which can decrease the energy growth barrier to the order of thermal energy.

In the carbonated zone of the C-S-H paste (Fig. 7-a), and between 0 and $40 \mathrm{~mm}$ from the exposed surface, no signal related to C-S-H was detected using ${ }^{29} \mathrm{Si}$ NMR. Rather, large resonances $\left(\mathrm{Q}^{3}\right.$ gel and $\mathrm{Q}^{4}$ gel ca. 100 and $110 \mathrm{ppm}$, respectively) could be observed. This indicated that the C-S-H was completely degraded/dissolved and that silica chains polymerised to form an amorphous silica product (silica gel) [87]. This confirmed the observations made using XRD (Figs. 3 and 5). In the carbonation front (around 43.8-44.6 mm), there was decreased evidence of silica gel but the C-S-H was obviously affected by carbonation, because the relative intensities of the $Q^{1}$ and $Q^{2}$ environments were different from those of the non-carbonated C-S-H (beyond $47.6 \mathrm{~mm}$ ) and typical of a more polymerised environment. This indicated that the $\mathrm{C} / \mathrm{S}$ ratio of the C-S-H had decreased [88-91] and that Ca was taken from the $\mathrm{C}-\mathrm{S}-\mathrm{H}$ structure.

Once again, the results from the $\mathrm{C}_{3} \mathrm{~S}$ paste were somewhat different from those of the C-S-H paste (Fig. 7-b). The C-S-H was almost completely degraded very close to the surface exposed to $\mathrm{CO}_{2}(0-2 \mathrm{~mm})$, but a significant amount remained in the carbonated zone (between 2 and $19 \mathrm{~mm}$ ), with a C/S ratio decrease that was evidenced by the decrease of the relative intensities of the $\mathrm{Q}^{1}$ and $\mathrm{Q}^{2}$ compared to the non-carbonated part.
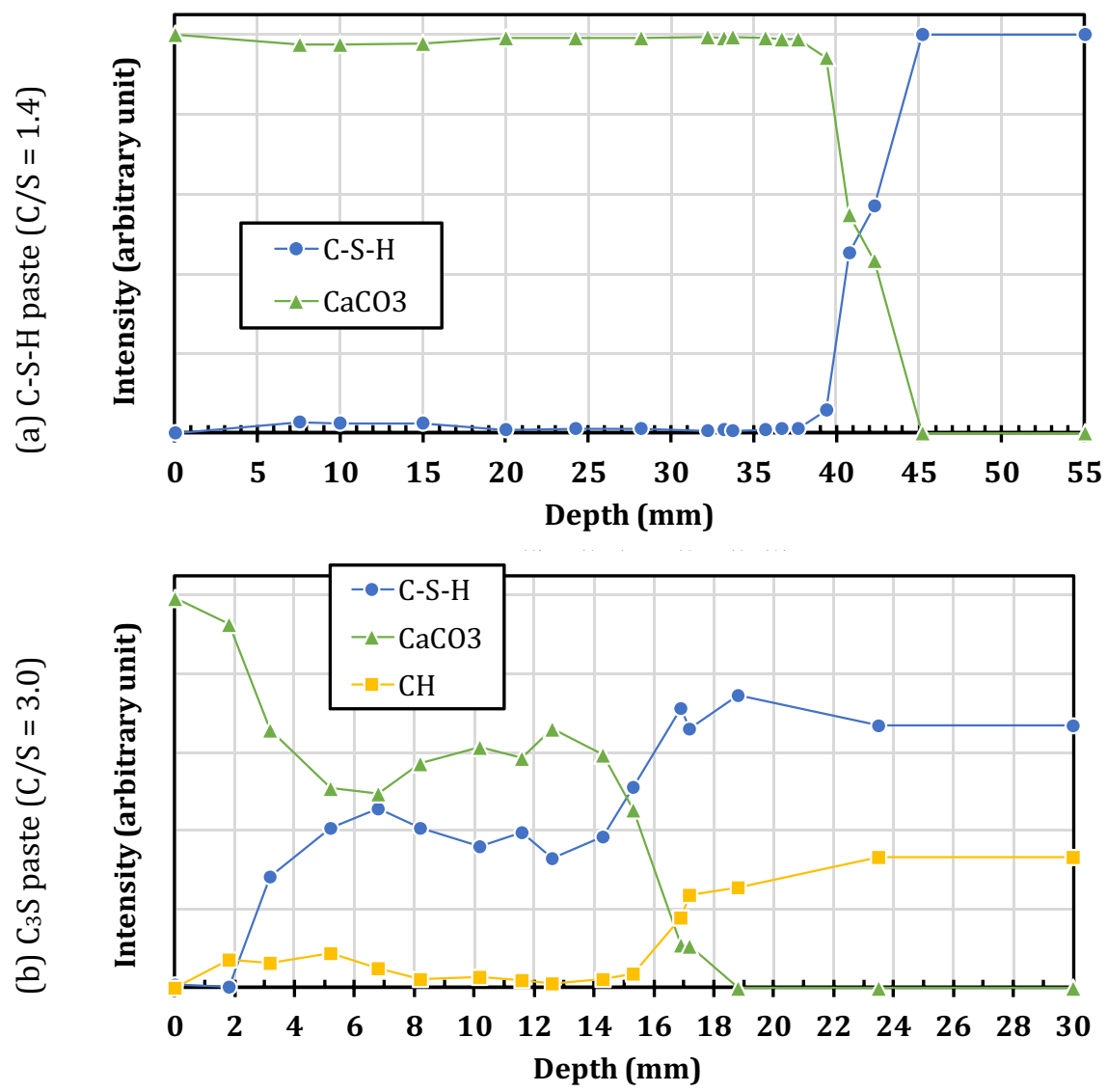

Fig. 5. Mineralogical assemblage after accelerated carbonation (316 and 326 days for the C-S-H and $\mathrm{C}_{3} \mathrm{~S}$ pastes respectively) obtained using XRD. 

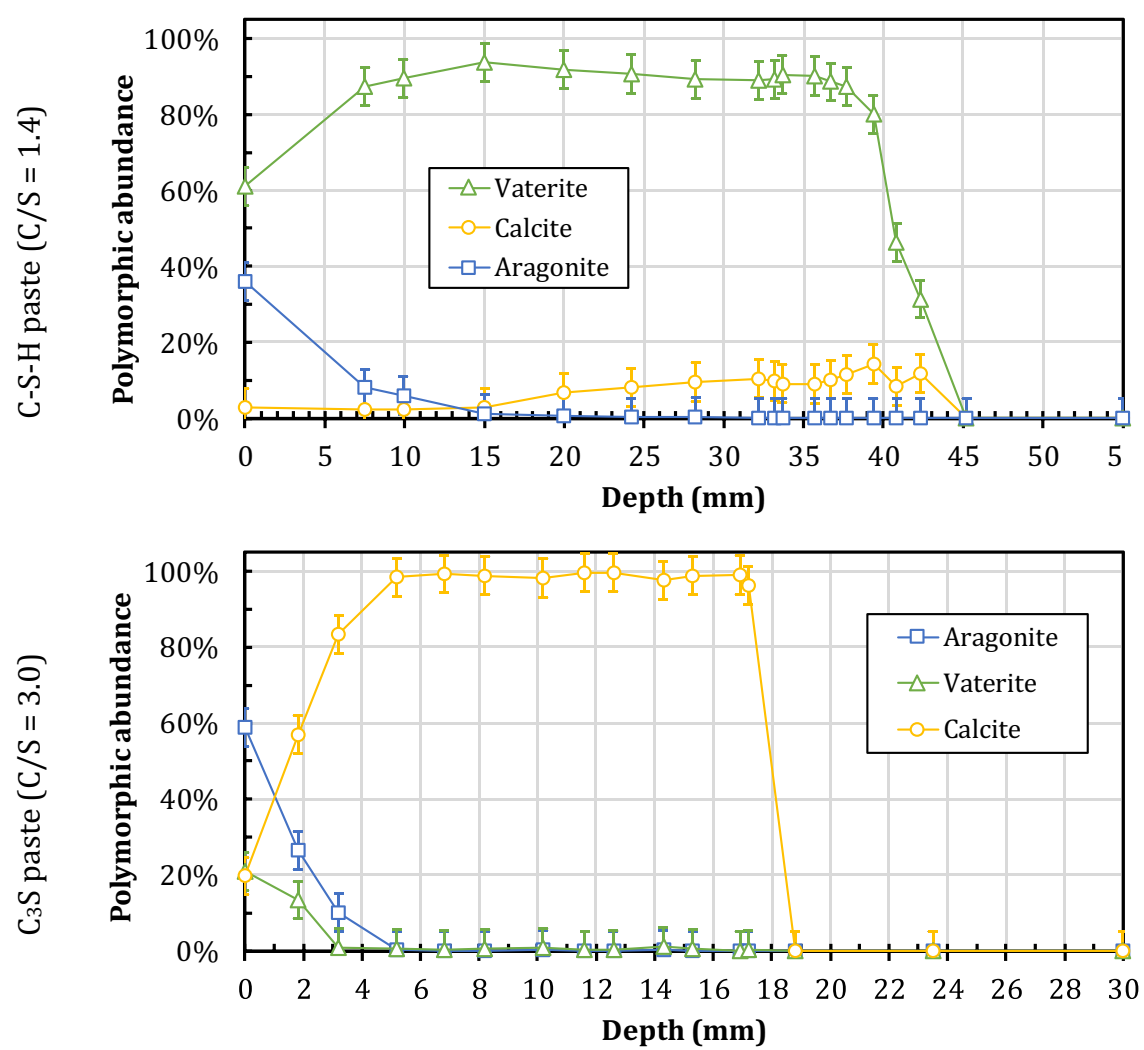

Fig. 6. $\mathrm{CaCO}_{3}$ polymorphic abundance (\%wt) in the carbonated zone after accelerated carbonation (316 and 326 days for the $\mathrm{C}-\mathrm{S}-\mathrm{H}$ (top) and $\mathrm{C}_{3} \mathrm{~S}$ pastes (bottom) respectively) obtained using Rietveld refinement. The vertical bar represents the uncertainty of the quantification using Rietveld refinement (evaluated to $5 \%$ ).

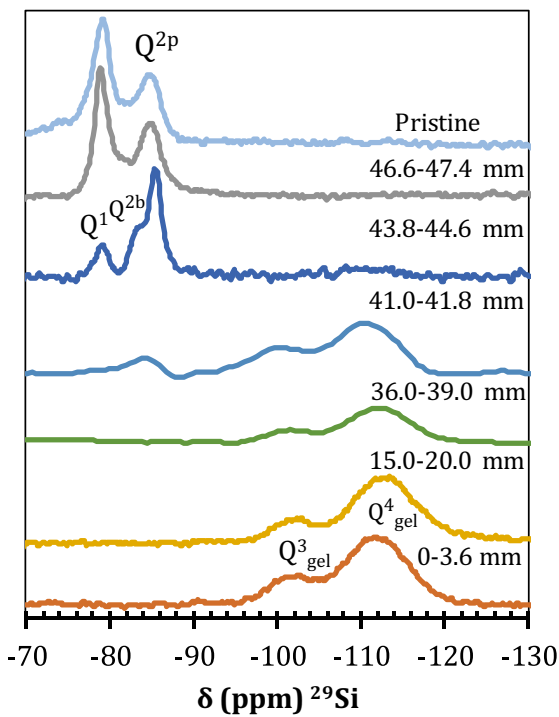

(a) C-S-H paste $(\mathrm{C} / \mathrm{S}=1.4)$

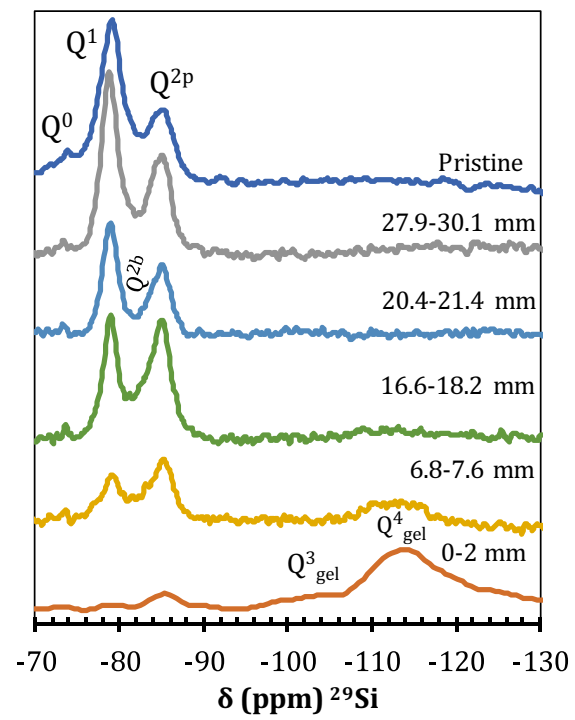

(b) $\mathrm{C}_{3} \mathrm{~S}$ paste $(\mathrm{C} / \mathrm{S}=3.0)$

Fig. 7. ${ }^{29} \mathrm{Si}$ NMR spectra of the C-S-H and $\mathrm{C}_{3} \mathrm{~S}$ pastes after accelerated carbonation (316 and 326 days for the C-S-H and $\mathrm{C}_{3} \mathrm{~S}$ pastes, respectively).

The quantitative mineralogical profile of calcium carbonate $(C \bar{C})$ that was obtained using TGA is presented in Fig. 8(a) for the C-S-H paste $(C / S=1.4)$. For the purposes of comparison, the calcium carbonate profile is presented together with that of C-S-H that was assessed from the ${ }^{29} \mathrm{Si}$ NMR results using:
$\% \mathrm{Si}(\mathrm{C}-\mathrm{S}-\mathrm{H})=\frac{\mathrm{Q}^{1}+\mathrm{Q}^{2 \mathrm{~b}}+\mathrm{Q}^{2 \mathrm{p}}}{\sum_{\mathrm{n}=0}^{4} \mathrm{Q}^{\mathrm{n}}}$

where $\% \mathrm{Si}(\mathrm{C}-\mathrm{S}-\mathrm{H})$ stands for the atomic fraction (at.\%) of total silicon present in the C-S-H.

The carbonation depth was about $40-45 \mathrm{~mm}$ and the carbonation front was quite sharp (Fig. 8-a). This was confirmed by both TGA (for 

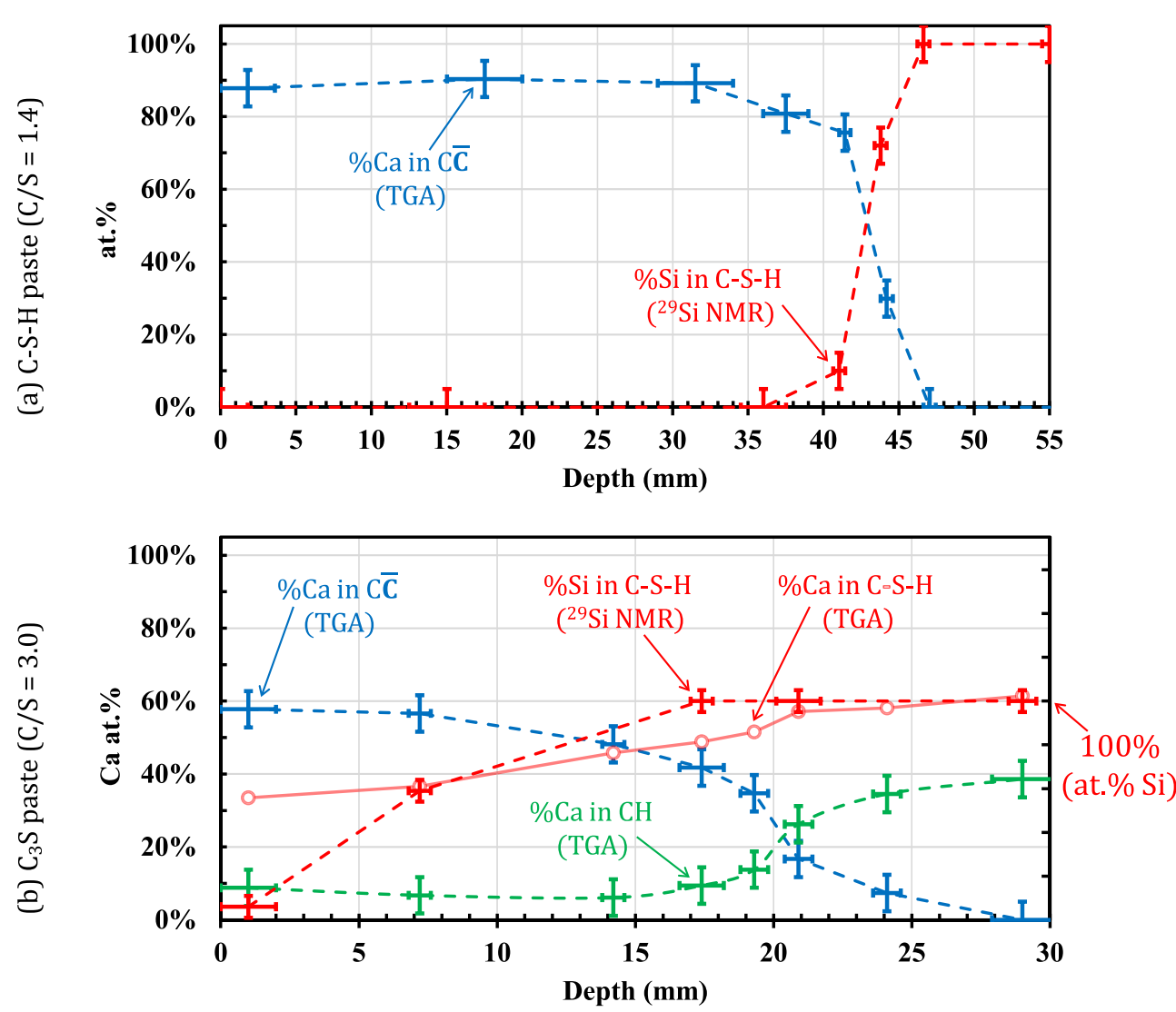

Fig. 8. Quantitative mineralogical profiles obtained using TGA and NMR after accelerated carbonation ( 316 and 326 days for the C-S-H and $\mathrm{C}_{3} \mathrm{~S}$ pastes, respectively). The horizontal bar represents the thickness of the disk that was sampled and tested using TGA. The vertical bar represents the uncertainty of measurement (evaluated to $5 \%$ ). Note that the scale of the $\% \mathrm{Si}(\mathrm{C}-\mathrm{S}-\mathrm{H})$ profile obtained using NMR was modified to ensure comparison with the $\% \mathrm{Ca}(\mathrm{C}-\mathrm{S}-\mathrm{H})$ profile obtained using TGA.

calcium carbonate $\mathrm{C} \overline{\mathrm{C}}$ ) and ${ }^{29} \mathrm{Si}$ NMR (for C-S-H). The Ca content in $\mathrm{CaCO}_{3}$ in the carbonated zone appeared to be lower than $100 \%$ (by about $10 \%$ on average). This did not mean that some C-S-H remained in the carbonated zone, as its absence was unambiguously proven using ${ }^{29}$ Si NMR (Figs. $7 \&$ 8-a). Rather, this could to be due to some discrepancy in the TGA quantification, because $\mathrm{CaCO}_{3}$ has been shown to sometimes decompose at temperatures lower than $600{ }^{\circ} \mathrm{C}[3,6,92,93]$, or this could indicate that some Ca was present in the silica gel instead of precipitating as $\mathrm{CaCO}_{3}$. In this latter case, considering that all the silica was present under the form of silica gel and that $10 \%$ of the Ca remained in the silica gel (Fig. 8-a), it was easy to estimate the $\mathrm{C} / \mathrm{S}$ ratio of the silica gel: $10 \%$ of the $\mathrm{C} / \mathrm{S}$ of the paste $=0.1 \times 1.4=0.14$.

The situation was not so clear for the $\mathrm{C}_{3} \mathrm{~S}$ paste (Fig. 8-b): the carbonation front was not well defined and the carbonation depth was lower than that of the C-S-H paste by two times: about $17-22 \mathrm{~mm}$. As already shown by XRD (Figs. 3 \& 5), portlandite remained in the carbonated zone, and its residual content was estimated to be $25 \%$ of the initial content (Table 3). Comparing the amounts of Ca in portlandite $\%$ $\mathrm{Ca}(\mathrm{CH})$ and calcium carbonate $\% \mathrm{Ca}(\mathrm{C} \overline{\mathrm{C}})$ obtained using TGA, it was possible to estimate the amount of $\mathrm{Ca}$ that remained in the $\mathrm{C}-\mathrm{S}-\mathrm{H} \% \mathrm{Ca}(\mathrm{C}$ $-\mathrm{S}-\mathrm{H}$ ) as follows:

Table 3

Amount of calcium involved in the carbonation reaction.

\begin{tabular}{lll}
\hline Paste & Amount of Ca carbonated & Value (mol/L of paste) \\
\hline C $_{3}$ S paste & $75 \%$ of $[\mathrm{CH}]+40 \%$ of $[\mathrm{C}-\mathrm{S}-$ & $0.75 \times 7.3+0.4 \times 1.7 \times 5.6=$ \\
& $\mathrm{H}]$ & 9.3 \\
C-S-H & $100 \%$ of $[\mathrm{C}-\mathrm{S}-\mathrm{H}]$ & $1.4 \times 7.0=9.8$ \\
paste & & \\
\hline
\end{tabular}

$\% \mathrm{Ca}(\mathrm{C}-\mathrm{S}-\mathrm{H})=100 \%-\% \mathrm{Ca}(\mathrm{CH})-\% \mathrm{Ca}(\mathrm{C} \overline{\mathrm{C}})$

The results indicate that, in the carbonated zone, the C-S-H retained almost $60 \%$ of its $\mathrm{Ca}$. This was more or less consistent with the results of ${ }^{29} \mathrm{Si}$ NMR even though both of them strongly differed near the cylinder surface (Fig. 8-b). This result made it possible to evaluate the amount of Ca that was involved in the carbonation of each paste (Table 3). For the $\mathrm{C}_{3} \mathrm{~S}$ paste, not all the $\mathrm{Ca}$ of $\mathrm{CH}$ or C-S-H was involved in carbonation: it corresponded only to $75 \%$ of $\mathrm{CH}$ and $40 \%$ of the C-S-H, whereas it corresponded to all the C-S-H for the C-S-H paste. Furthermore, despite a strong difference in their initial Ca content, the carbonation of the two pastes appeared to have yielded similar amounts of $\mathrm{CaCO}_{3}$ (9.3 versus $9.8 \mathrm{~mol} / \mathrm{L})$.

\subsection{Microstructure/cracking}

Carbonation led to a decrease in total porosity (from $10 \%$ to $20 \%$ ) and an increase in density (from 0.32 to $0.39 \mathrm{~g} / \mathrm{cm}^{3}$ ) (Table 4) as has been commonly observed [39,73,94-97]. It is noteworthy that the change in dry density induced by carbonation (i.e. induced by the fixation of $\mathrm{CO}_{2}$ ) was quite similar for the two pastes. This is surely consistent with the fact that the amounts of carbonated Ca were similar for the two pastes $\left(9.8\right.$ and $9.3 \mathrm{~mol} / \mathrm{L}$ of paste for the $\mathrm{C}-\mathrm{S}-\mathrm{H}$ and $\mathrm{C}_{3} \mathrm{~S}$ pastes, respectively, see Table 3 ). The reduction in porosity was twice higher for the C-S-H than for the $\mathrm{C}_{3} \mathrm{~S}$ paste, but this was explained simply by considering the phases that were present in the carbonated pastes and the corresponding volumes (see Section 5.1).

The pore size distribution was also significantly modified by carbonation (Fig. 9). In both cases, the bimodal distribution was shifted to an almost unimodal distribution located near $10 \mathrm{~nm}[35,55]$, the 
Porosity and density of the carbonated pastes.

\begin{tabular}{llll}
\hline & $\begin{array}{l}\text { C-S-H paste }(\mathrm{C} / \mathrm{S} \\
=1.4)\end{array}$ & $\begin{array}{l}\text { C3S paste }(\mathrm{C} / \mathrm{S}= \\
3.0)\end{array}$ & Unit \\
\hline Density (saturated) & 1.98 & 2.11 & $\begin{array}{l}\mathrm{g} / \\
\mathrm{cm}^{3}\end{array}$ \\
$\begin{array}{l}\left.\text { Total porosity (drying at } 80{ }^{\circ} \mathrm{C}\right) \\
\begin{array}{l}\text { Total porosity (drying at } \\
\left.105^{\circ} \mathrm{C}\right)\end{array}\end{array}$ & $35 \%$ & $28 \%$ & - \\
$\begin{array}{l}\left.\text { Dry density (drying at } 80{ }^{\circ} \mathrm{C}\right) \\
\left.\text { Dry density (drying at } 105{ }^{\circ} \mathrm{C}\right)\end{array}$ & 1.63 & $29 \%$ & - \\
$\begin{array}{l}\text { Change in porosity (drying at } \\
\left.80{ }^{\circ} \mathrm{C}\right)^{\mathrm{a}}\end{array}$ & $-20 \%$ & 1.83 & $\begin{array}{l}\mathrm{g} / \\
\mathrm{cm}^{3}\end{array}$ \\
$\begin{array}{l}\text { Change in dry density (drying } \\
\left.\text { at } 80{ }^{\circ} \mathrm{C}\right)^{\mathrm{a}}\end{array}$ & +0.39 & 1.82 & $\begin{array}{l}\mathrm{cm} \\
\mathrm{cm}^{3}\end{array}$ \\
\hline
\end{tabular}

${ }^{\text {a }}$ See Table 2 for the porosity and density values of the non-carbonated pastes.

intensity of which seemed to depend on the degree of carbonation (close to $100 \%$ for the $\mathrm{C}-\mathrm{S}-\mathrm{H}$ paste and limited for the $\mathrm{C}_{3} \mathrm{~S}$ paste). In the carbonated C-S-H paste, the amount of the C-S-H pores ( $3 \mathrm{~nm}$ in diameter) was almost nil. This was consistent with the ${ }^{29} \mathrm{Si}$ NMR results that showed that the C-S-H was depleted after carbonation. This was not the case for the carbonated $\mathrm{C}_{3} \mathrm{~S}$ paste for which $60 \%$ of the C-S-H remained after carbonation (Table 3 ). Another point of interest was the change in critical pore diameter (the diameter corresponding to the major peak encountered when moving from big to small pores) [98,99]: the pore structure after carbonation was coarsened for the C-S-H paste (the critical pore diameter was shifted from $20 \mathrm{~nm}$ to $150 \mathrm{~nm}$ by carbonation) whereas the critical pore diameter was reduced from $35 \mathrm{~nm}$ to $20 \mathrm{~nm}$ by carbonation (for the $\mathrm{C}_{3} \mathrm{~S}$ paste). On this basis, carbonation would then be expected to increase the transport properties (and then gas diffusion) of the C-S-H paste and to reduce those of the $\mathrm{C}_{3} \mathrm{~S}$ paste. Note that this divergent behaviour has already been observed for OPC and substituted binders [34,35,100].

Fig. 10 presents two scans that were obtained using X- $\mu$ CT after carbonation. The carbonated zones are clearly visible in light grey. It can be observed that the carbonation front appeared tortuous in both cases and that the carbonation depth values were consistent with those obtained using XRD (Fig. 5) and TGA (Fig. 8). The carbonated zone of the C-S-H paste appeared to be severely cracked, especially for the first 10 $\mathrm{mm}$. Conversely, the carbonated zone of the $\mathrm{C}_{3} \mathrm{~S}$ paste only shows a few thinner cracks.

Thorough examination of the C-S-H paste scan revealed the presence of four different zones in the cylinder (Fig. 11). The first (I) corresponded to the first $10 \mathrm{~mm}$ of the carbonated zone. It was severely cracked (crazing) and the grey level was almost uniform due to complete

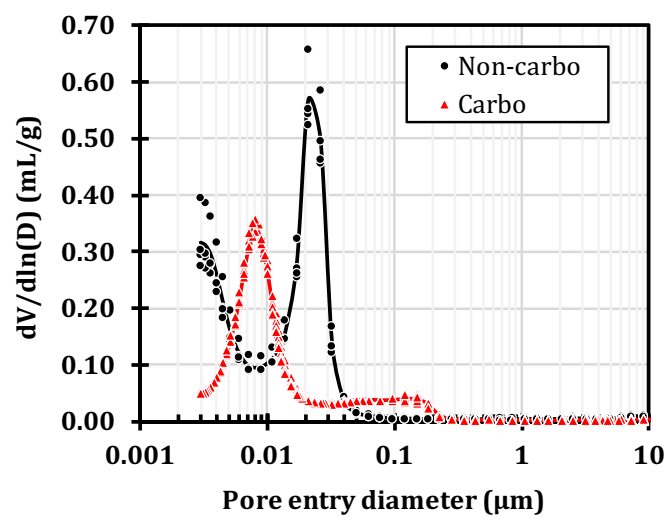

(a) $\mathrm{C}-\mathrm{S}-\mathrm{H}$ paste $(\mathrm{C} / \mathrm{S}=1.4)$ carbonation and C-S-H decalcification. The second (II, between 10 and $40 \mathrm{~mm}$ ) was somewhat different. The cracks were thinner than those of the first zone and almost parallel. In addition, strong heterogeneities in grey levels could be observed (Fig. 12). Here, it was assumed that cracks were generated by restrained carbonation shrinkage and that $\mathrm{CO}_{2}$ was able to quickly diffuse into these open cracks, helping in carbonating the matrix close to the cracks. This was believed to have induced the observed heterogeneities. It must be noted, though, that no significant differences were obtained between zones I and II using XRD and NMR.

The third zone (III) corresponded to what appeared as the carbonation front (between 40 and $45 \mathrm{~mm}$ ) using TGA (Fig. 8-a) and XRD (Fig. 5-a), where C-S-H were progressively decalcified. Similar to zone II, zone III presented strong heterogeneities in grey level. This zone was thought to be cracked (but with openings smaller than the XCT resolution, assumed to be less than $1 \mu \mathrm{m}$ ) which led to the coexistence of carbonated and non-carbonated paste within the same region. The last zone (IV) corresponded to the non-carbonated zone (almost uniform dark grey level).

Examination of the $\mathrm{C}_{3} \mathrm{~S}$ paste showed three main zones (Fig. 13). The first (I, the first five millimetres from the surface) appeared in light grey (denser than the rest) and was then expected to be the most carbonated part of the cylinder. This corresponded quite well with the mineralogical results that showed that the $\mathrm{CaCO}_{3}$ content was maximal. The grey level of the second zone (II, from 5 to $20 \mathrm{~mm}$ ) was darker than that of zone I, indicating that it was less dense and then less carbonated. This was verified by the mineralogical results that showed that $\mathrm{C}-\mathrm{S}-\mathrm{H}$ and $\mathrm{CH}$ remained in significant amounts. The last zone (III) corresponded to the non-carbonated part (darker grey). The carbonation front appeared to be tortuous due to the presence of few cracks that locally provided pathways for $\mathrm{CO}_{2}$ and increased the carbonation depth close to the cracks.

\subsection{Carbonation rate/gas diffusion}

Fig. 14 shows the progress of carbonation depth with the square root of time. All the techniques used (X- $\mu \mathrm{CT}$, phenolphthalein and XRD) were in good agreement. As expected, the carbonation rate of the C-S-H paste was higher than that of the $C_{3} S$ paste $\left(2.1 \mathrm{~mm} / \mathrm{d}^{0.5}\right.$ versus $\left.1.1 \mathrm{~mm} / \mathrm{d}^{0.5}\right)$. Here, the reduced quantity of calcium in the C-S-H paste may have played a role in increasing the carbonation rate [101-105].

The results of the gas diffusion tests also provided valuable information. The value of the diffusion coefficient of the carbonated $\mathrm{C}_{3} \mathrm{~S}$ paste was $2.7 \times 10^{-8} \mathrm{~m}^{2} / \mathrm{s}$. This value is in good agreement with results usually observed in carbonated OPC pastes [39,100]. Because it was severely cracked (Fig. 10), it was impossible to measure the gas diffusion coefficient of the C-S-H paste. Instead, the gas diffusion coefficient was assessed using Papadakis' model (Eq. (3)). In doing so, the experimental

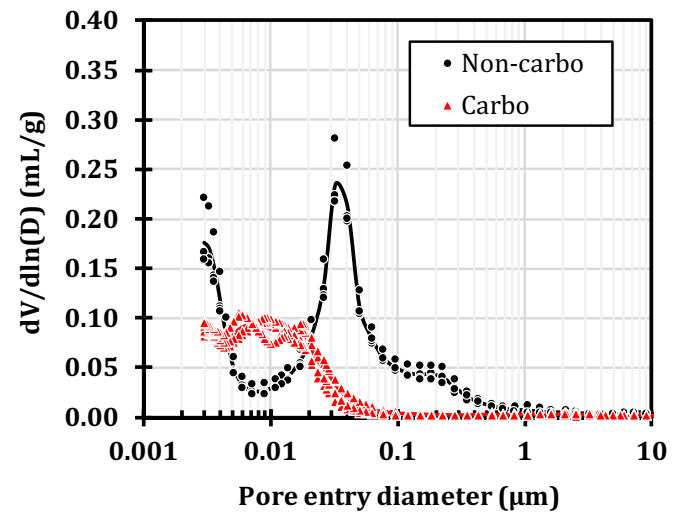

(b) $\mathrm{C}_{3} \mathrm{~S}$ paste $(\mathrm{C} / \mathrm{S}=3.0)$

Fig. 9. Pore-entry size distribution obtained using MIP after accelerated carbonation. 


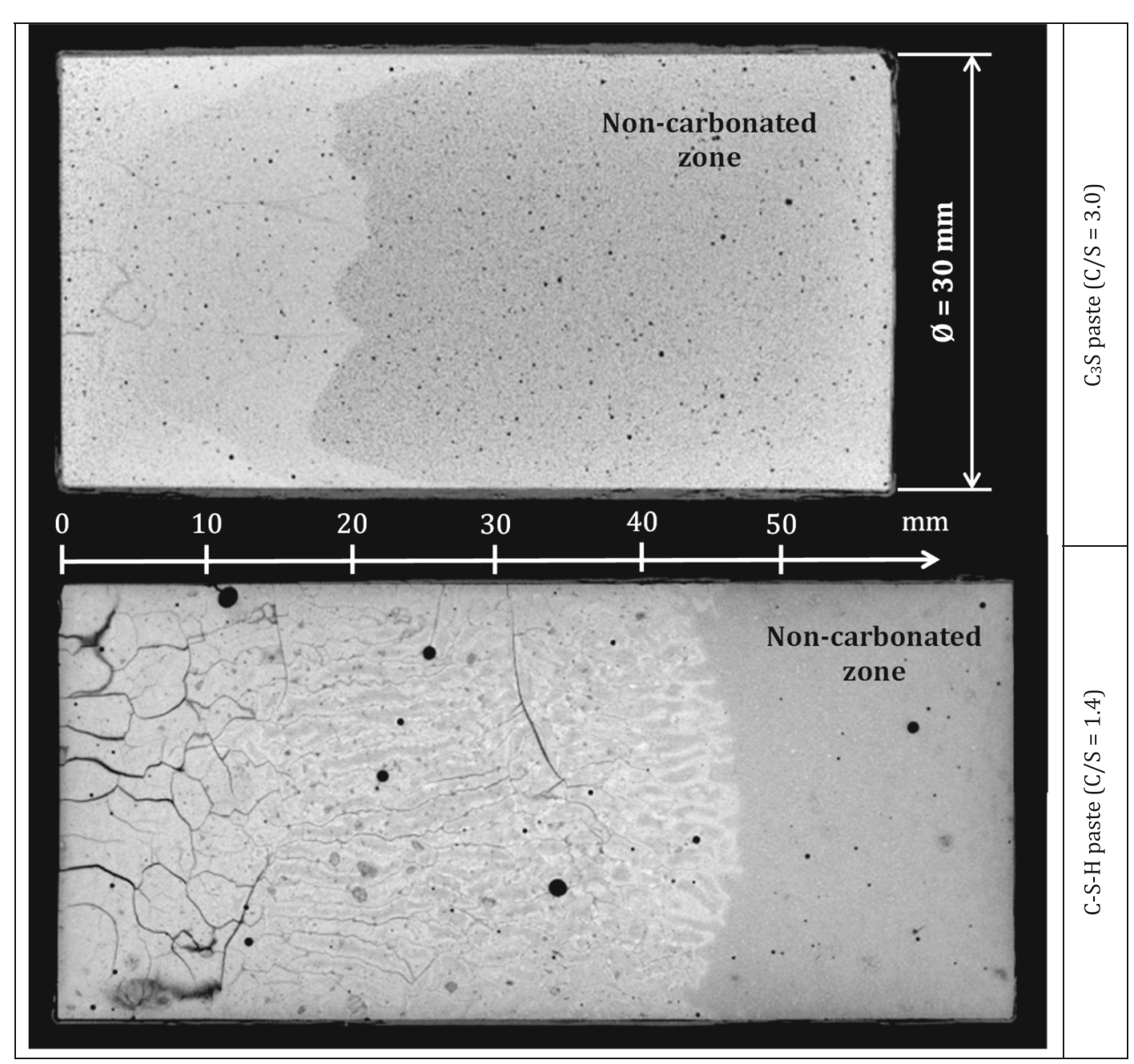

Fig. 10. Cracking pattern observed using X- $\mu \mathrm{CT}$ after accelerated carbonation ( 316 and 326 days for the $\mathrm{C}-\mathrm{S}-\mathrm{H}$ and $\mathrm{C}_{3} \mathrm{~S}$ pastes, respectively).

carbonation rate $k$ was used as input data. Firstly, and for validation purposes, the model by Papadakis was also used to evaluate the diffusion coefficient of the carbonated $\mathrm{C}_{3} \mathrm{~S}$ paste. Thus, the quantity of carbonatable calcium $[\mathrm{Ca}]_{\text {carbo }}$ was estimated using the TGA results (Fig. 8):

$$
[\mathrm{Ca}]_{\text {carbo }}=75 \% \text { of }[\mathrm{CH}]+1.7 \times 40 \% \text { of }[\mathrm{C}-\mathrm{S}-\mathrm{H}]=9.3 \mathrm{~mol} / \mathrm{L} \text { of paste }
$$

The diffusion coefficient of the carbonated $\mathrm{C}_{3} \mathrm{~S}$ paste was evaluated as $5.2 \times 10^{-8} \mathrm{~m}^{2} / \mathrm{s}$. This was twice the measured value $\left(2.7 \times 10^{-8} \mathrm{~m}^{2}\right.$ / $\mathrm{s})$, but the order of magnitude of the diffusion coefficient estimated using Papadakis' model was correct. For the C-S-H paste, all the C-S-H were assumed to be available for carbonation, which was supported by the NMR results (Fig. 7). Consequently, E- 3 simply became:

$D_{\mathrm{CO}_{2}}^{c}=\left(\frac{[\mathrm{Ca}]_{\text {carbo }}}{2\left[\mathrm{CO}_{2}\right]}\right) k^{2}=1.4 k^{2} \frac{[\mathrm{C}-\mathrm{S}-\mathrm{H}]}{\left[\mathrm{CO}_{2}\right]}$

where

$[\mathrm{Ca}]_{\text {carbo }}=1.4 \times[\mathrm{C}-\mathrm{S}-\mathrm{H}]=9.8 \mathrm{~mol} / \mathrm{L}$ of paste

$\left[\mathrm{CO}_{2}\right]=1.25 \times 10^{-3} \mathrm{~mol} / \mathrm{L}\left(3 \% \mathrm{CO}_{2}\right)$.

The value of the diffusion coefficient of $\mathrm{CO}_{2}$ in the carbonated C-S-H paste $(\mathrm{C} / \mathrm{S}=1.4)$ was evaluated to be $20.0 \times 10^{-8} \mathrm{~m}^{2} / \mathrm{s}$; one order of magnitude greater than the value measured in the carbonated $\mathrm{C}_{3} \mathrm{~S}$ paste. This strong difference was explained by two concomitant phenomena: (1) the critical pore diameter of the carbonated C-S-H paste was higher than that of the carbonated $\mathrm{C}_{3} \mathrm{~S}$ paste (150 nm versus $20 \mathrm{~nm}$, see Fig. 9) and (2) the significant cracking induced by carbonation in the C-S-H paste (Fig. 10). Because the amount of pores of entry diameter $150 \mathrm{~nm}$ remained limited in the carbonated C-S-H paste, cracking was believed to be the major cause for the high gas diffusion coefficient in line with the conclusions of Auroy et al. [35] and Dutzer et al. [100].

\subsection{Carbonation shrinkage}

Fig. 15 presents the length variation of the smallest cylinders (Ø14 $\mathrm{mm}$ ) that were submitted for drying and then accelerated carbonation. The drying shrinkage of the $\mathrm{C}_{3} \mathrm{~S}$ paste quickly reached a stable value $(0.3 \%=3 \mathrm{~mm} / \mathrm{m})$ that was consistent with the results of Mindess et al. [106], whereas the C-S-H paste kept slowly shrinking and was not stabilised even at 195 days. This could be due to (1) the refined pore structure of the C-S-H paste (Fig. 9) that induced very low water transport properties and (2) to the atmospheric carbonation $(0.04 \%$ $\mathrm{CO}_{2}$ ) of the C-S-H paste during drying that could have induced some carbonation shrinkage during the preliminary drying phase. After 195 days of drying, the specimens were subjected to $3 \% \mathrm{CO}_{2}$, which immediately generated additional shrinkage. Assuming that there was no interaction between the drying and carbonation, and that drying ended at 195 days, the carbonation shrinkage was simply estimated by subtracting the contribution of drying: $\varepsilon^{c}=\varepsilon^{t o t}-\varepsilon^{d}$. The shrinkage of the $\mathrm{C}$ $\mathrm{S}-\mathrm{H}$ paste appeared to be much higher than that of the $\mathrm{C}_{3} \mathrm{~S}$ paste (Table 5). 

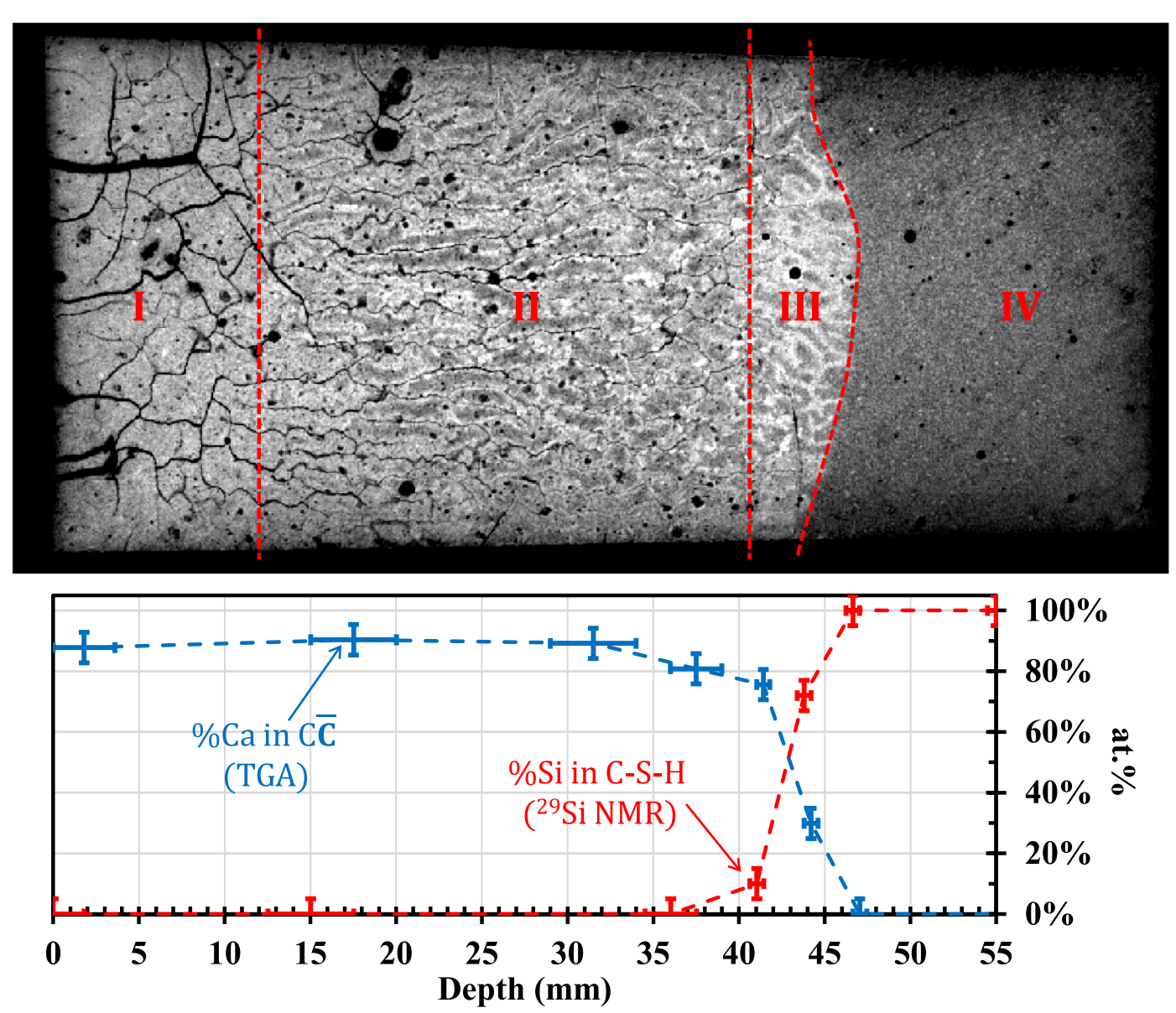

Fig. 11. View of the four observed zones using X- $\mu \mathrm{CT}$ in the C-S-H paste after carbonation (316 days). For comparison, the corresponding mineralogical profile of Fig. 8(a) is reproduced to scale.

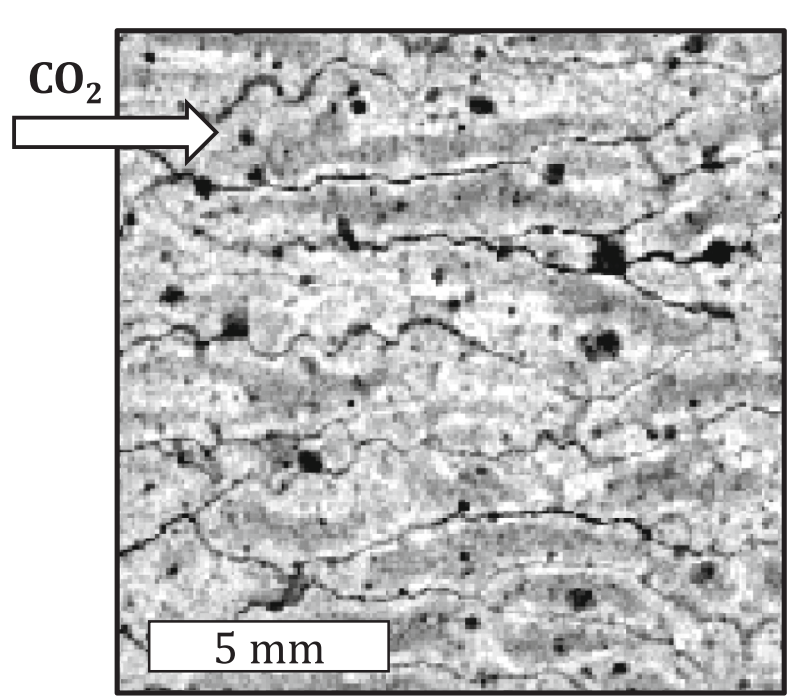

Fig. 12. Close-up of zone II of the C-S-H paste and view of the cracks and scatter in grey level.

\section{Discussion: linking mineralogy with structural changes}

\subsection{Volume change}

All the above-mentioned results were used to evaluate the change in solid volume and weight induced by carbonation. The $\mathrm{C} / \mathrm{S}=1.4$ paste was examined first because it was the simplest system. The non-carbonated paste was considered to be a porous medium made of only C-S-H (with $\mathrm{C} / \mathrm{S}=1.4$, cf. Fig. 16). The C-S-H carbonation reaction was assumed to be the following:

$\mathrm{C}_{1.4}-\mathrm{S}-\mathrm{H}_{1.4}+1.4 \overline{\mathrm{C}} \rightarrow 1.4 \mathrm{C} \overline{\mathrm{C}}($ Vaterite $)+\mathrm{S}-\mathrm{H}_{\mathrm{t}}+(1.4-\mathrm{t}) \mathrm{H}$

As observed using XRD, the $\mathrm{CaCO}_{3}$ resulting from the carbonation of the C-S-H was assumed to be vaterite (Fig. 6). Without further information, the H/S ratio of the C-S-H was assumed to be 1.4 so that the C-S$\mathrm{H}$ specific gravity was close to 2.604 [25], and the end product of the decalcification of the C-S-H was assumed to be a hydrated silica-gel (S-H, Fig. 7).

Table 6 and Table 7 detail the volume and mass calculations for the different phases present in the non-carbonated and fully carbonated C-S$\mathrm{H}$ paste $(\mathrm{C} / \mathrm{S}=1.4)$.

If we first consider the non-carbonated C-S-H paste $(\mathrm{C} / \mathrm{S}=1.4)$, the $\mathrm{C}-\mathrm{S}-\mathrm{H}$ molar volume can be easily calculated (please note that here we used the porosity obtained by drying at $80^{\circ} \mathrm{C}$, Table 2):

$V_{m}(C-S-H)=\frac{1-\varnothing_{n c}}{[C-S-H]}=\frac{1-0.35}{7} \approx 69 \mathrm{~cm}^{3} / \mathrm{mol}$

The obtained value is close to that measured by Allen et al. [24] (72 $\left.\mathrm{cm}^{3} / \mathrm{mol}\right)$ and further used by Jennings [25] $\left(72 \mathrm{~cm}^{3} / \mathrm{mol}\right.$ for $\left.\mathrm{C} / \mathrm{S}=1.7\right)$ and the value computed using molecular dynamics by Pellenq et al. [23] $\left(70.8 \mathrm{~cm}^{3} / \mathrm{mol}\right.$ for $\left.\mathrm{C} / \mathrm{S}=1.65\right)$.

After complete carbonation of the C-S-H paste $(\mathrm{C} / \mathrm{S}=1.4)$, the same kind of calculation was performed to estimate the properties of the silica gel (S-H), namely molar volume $V_{m}(S-H)$ and molar mass $M_{m}(S-H)$ : 

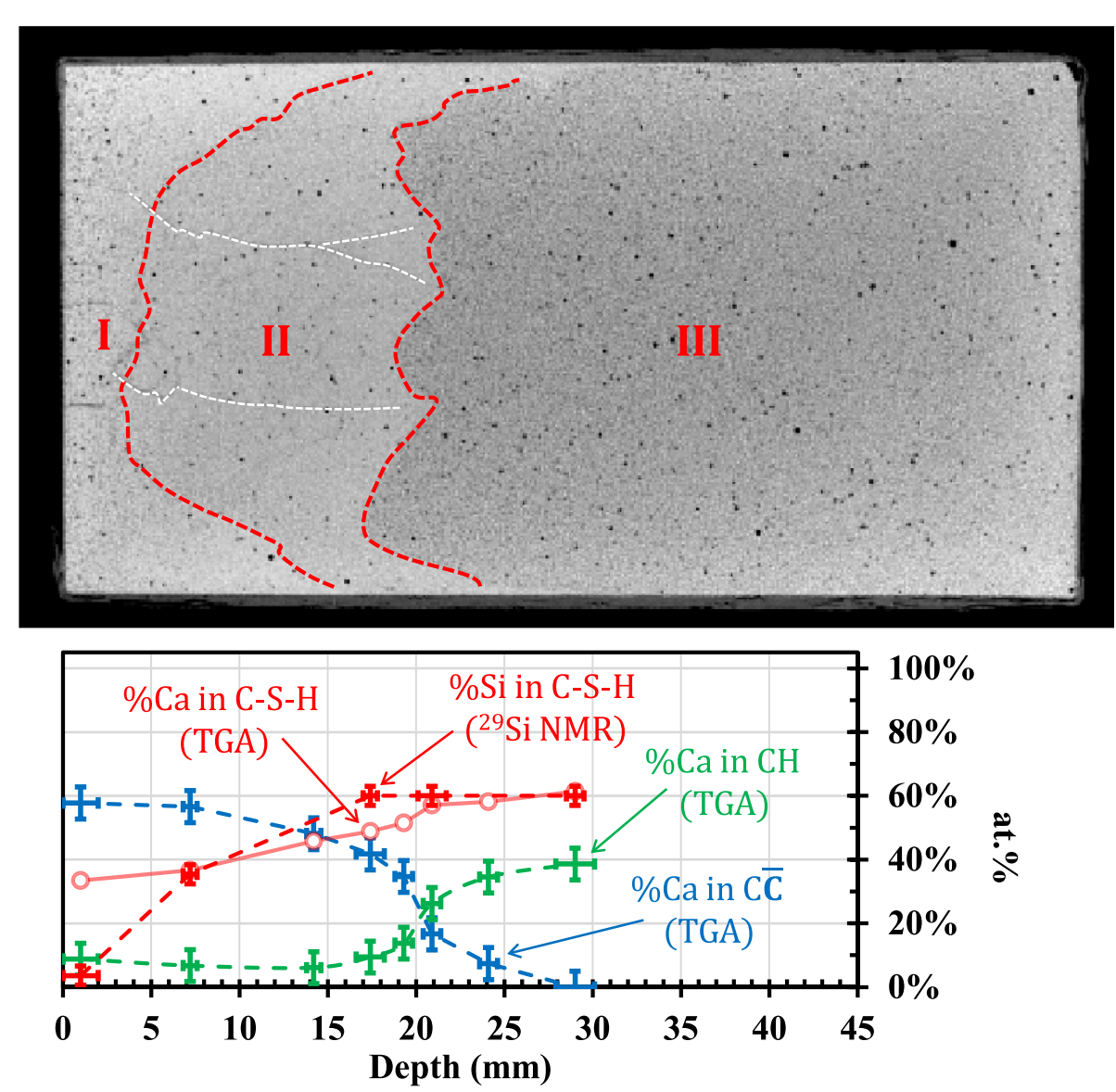

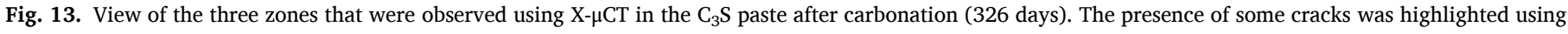
white dashed lines. For comparison, the corresponding mineralogical profile of Fig. 8(b) is reproduced to scale.
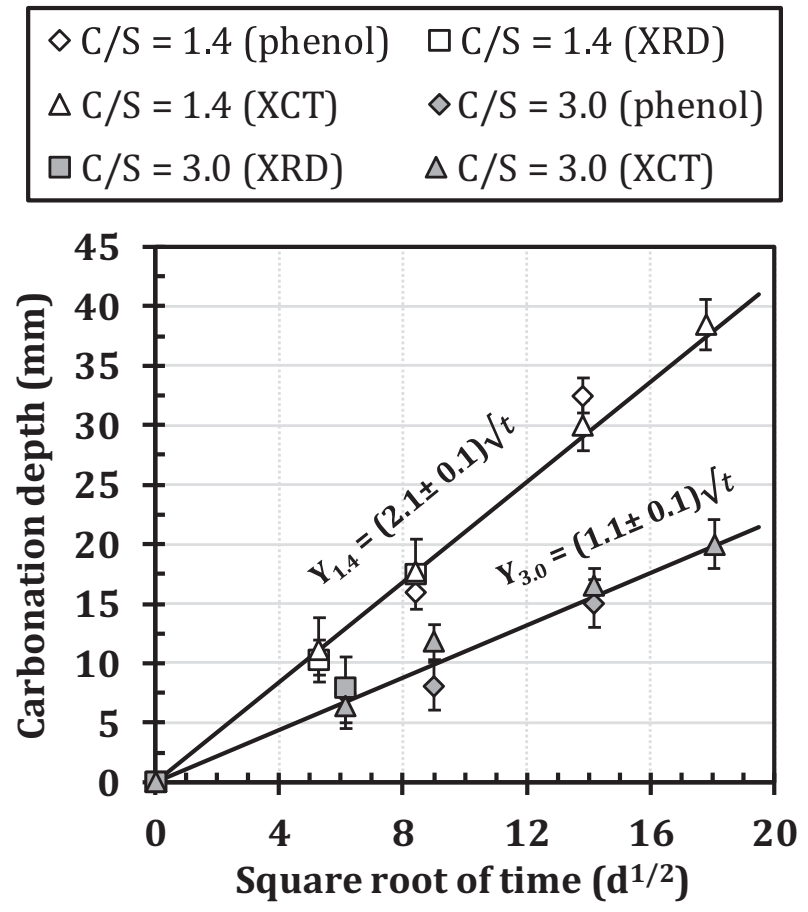

Fig. 14. Carbonation rates of the two pastes obtained using phenolphthalein, XRD and XCT.

$$
\begin{aligned}
& V_{m}(S-H)=\frac{\left(1-\varnothing_{c}\right)-1.4[C-S-H] V_{m}(\text { Vat })}{1.4[C-S-H]} \approx 40 \mathrm{~cm}^{3} / \mathrm{mol} \\
& M_{m}(S-H)=\frac{\rho_{d}^{c}-1.4[C-S-H] M_{m}(\text { Vat })}{1.4[C-S-H]} \approx 93 \mathrm{~g} / \mathrm{mol}
\end{aligned}
$$

The case of the $\mathrm{C}_{3} \mathrm{~S}$ paste $(\mathrm{C} / \mathrm{S}=3.0)$ was more complicated than the $\mathrm{C}-\mathrm{S}-\mathrm{H}$ paste $(\mathrm{C} / \mathrm{S}=1.4)$, because the non-carbonated paste included portlandite $(\mathrm{CH})$ in addition to $\mathrm{C}-\mathrm{S}-\mathrm{H}$ (Fig. 17). Moreover, carbonation was incomplete and then the remaining hydrates $(\mathrm{CH}$ and $\mathrm{C}-\mathrm{S}-\mathrm{H})$ coexisted with the end-products of carbonation (silica gel and calcium carbonate) in the carbonated paste (Fig. 17). It must be noted that we have implicitly assumed that a C-S-H with C/S lower than 1.7 could be described by an ad-hoc combination of silica gel and C-S-H of C/S $=1.7$. Alternatively, it would have been necessary to describe the link between $\mathrm{C} / \mathrm{S}$ and molar volume just like in the work of $\mathrm{Wu} \& \mathrm{Ye}[28]$, but this would have been much more difficult and uncertain.

Following the mineralogical observations (XRD and ${ }^{29} \mathrm{Si}$ NMR, see Section 4.1), the carbonation of $\mathrm{CH}$ and C-S-H was assumed to precipitate calcite (neither aragonite nor vaterite) and silica gel $(\mathrm{S}-\mathrm{H})$; note that the C-S-H was considered to be in the form $\mathrm{C}_{1.7}-\mathrm{S}-\mathrm{H}_{1.8}$ [25]:

$$
\left\{\begin{array}{c}
\mathrm{CH}+\overline{\mathrm{C}} \rightarrow \mathrm{C} \overline{\mathrm{C}}(\text { Calcite })+\mathrm{H} \\
\mathrm{C}_{1.7}-\mathrm{S}-\mathrm{H}_{1.8}+1.7 \overline{\mathrm{C}} \rightarrow 1.7 \mathrm{C} \overline{\mathrm{C}}(\text { Calcite })+\mathrm{S}-\mathrm{H}_{\mathrm{t}}+(1.8-\mathrm{t}) \mathrm{H}
\end{array}\right.
$$

Table 8 and Table 9 detail the volume and mass calculations of all the different phases present in the non-carbonated and (partially) carbonated $\mathrm{C}_{3} \mathrm{~S}$ paste $(\mathrm{C} / \mathrm{S}=3.0)$.

As for the $\mathrm{C}-\mathrm{S}-\mathrm{H}$ paste $(\mathrm{C} / \mathrm{S}=1.4)$, the results of the non-carbonated $\mathrm{C}_{3} \mathrm{~S}$ paste were used to evaluate the molar volume of the $\mathrm{C}-\mathrm{S}-\mathrm{H}$, according to: 


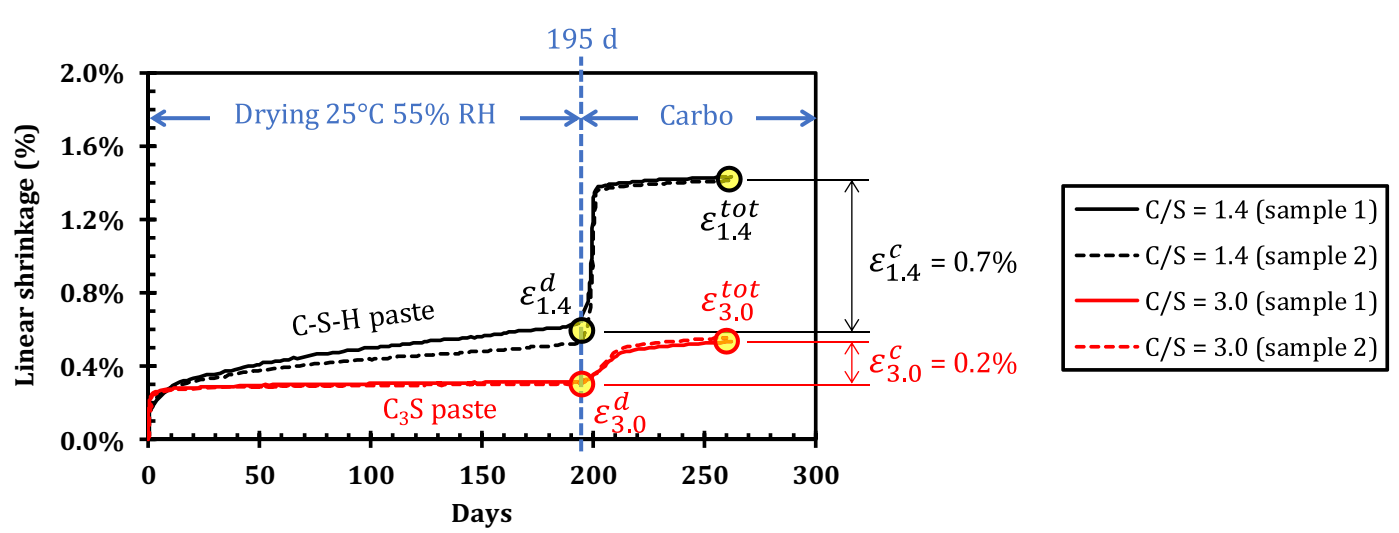

Fig. 15. Variation in length of the $\varnothing 14 \mathrm{~mm}$ cylinders exposed to drying $\left(25{ }^{\circ} \mathrm{C} 55 \% \mathrm{RH}\right)$ and then accelerated carbonation $\left(25{ }^{\circ} \mathrm{C}\right.$, $55 \% \mathrm{RH}$ and $\left.3 \% \mathrm{CO}_{2}\right)$.

Table 5

Results of the carbonation shrinkage tests.

\begin{tabular}{llll}
\hline Paste & $\begin{array}{l}\text { Total shrinkage } \\
\varepsilon^{\text {tot }}\end{array}$ & $\begin{array}{l}\text { Drying } \\
\text { shrinkage } \varepsilon^{d}\end{array}$ & $\begin{array}{l}\text { Carbonation } \\
\text { shrinkage } \varepsilon^{c}\end{array}$ \\
\hline $\begin{array}{l}\text { C-S-H paste }(\mathrm{C} / \mathrm{S} \\
\quad 1.4)\end{array}$ & $\begin{array}{l}1.4 \%(14 \mathrm{~mm} / \\
\mathrm{m})\end{array}$ & $0.7 \%(7 \mathrm{~mm} / \mathrm{m})$ & $0.7 \%(7 \mathrm{~mm} / \mathrm{m})$ \\
$\begin{array}{c}\mathrm{C}_{3} \mathrm{~S} \text { paste }(\mathrm{C} / \mathrm{S}= \\
\text { 3.0) }\end{array}$ & $0.5 \%(5 \mathrm{~mm} / \mathrm{m})$ & $0.3 \%(3 \mathrm{~mm} / \mathrm{m})$ & $0.2 \%(2 \mathrm{~mm} / \mathrm{m})$ \\
& & &
\end{tabular}

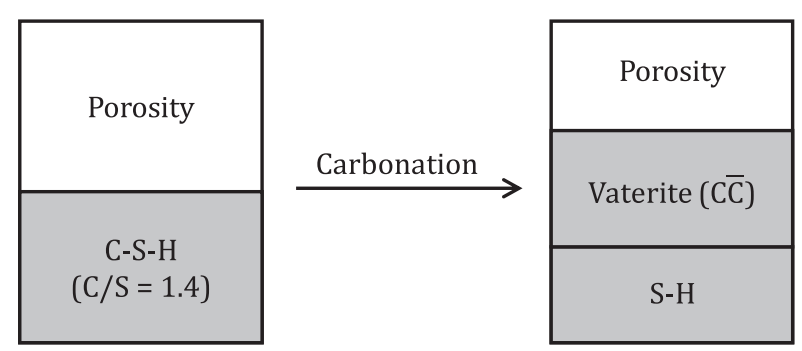

Non carbonated paste

Carbonated paste

Fig. 16. Assumed effect of carbonation on the C-S-H paste; the C-S-H are fully carbonated and replaced by silica gel and calcium carbonate (vaterite).
Table 7

Volume and mass of the different phases in the fully carbonated C-S-H paste (C) $\mathrm{S}=1.4)$.

\begin{tabular}{lll}
\hline Phase & Volume & Mass \\
\hline Voids & $\emptyset_{c}$ & 0 \\
Vaterite & $1.4[\mathrm{C}-\mathrm{S}-\mathrm{H}] V_{m}($ vat $)$ & $1.4[\mathrm{C}-\mathrm{S}-\mathrm{H}] M_{m}$ (vat) \\
S-H & $\left(1-\emptyset_{c}\right)-1.4[\mathrm{C}-\mathrm{S}-\mathrm{H}] V_{m}($ vat $)$ & $\rho_{d}^{c}-1.4[\mathrm{C}-\mathrm{S}-\mathrm{H}] M_{m}$ (vat) \\
Total & 1 & $\rho_{d}^{c}$ \\
\hline
\end{tabular}

$\emptyset_{c}$ porosity of the carbonated paste.

$\rho_{d}^{c}$ dry density of the carbonated paste.

[C-S-H] concentration of C-S-H in the non-carbonated paste.

$V_{m}$ (vat) molar volume of vaterite $\left(38 \mathrm{~cm}^{3} / \mathrm{mol}\right)$

$M_{m}$ (vat) molar mass of vaterite $(100.1 \mathrm{~g} / \mathrm{mol})$.

\section{Table 6}

Volume and mass of the different phases of the non-carbonated C-S-H paste $(\mathrm{C} / \mathrm{S}=1.4)$.

\begin{tabular}{lll}
\hline Phase & Volume & Mass \\
\hline Voids & $\emptyset_{\mathrm{nc}}$ & 0 \\
C-S-H & $\left(1-\emptyset_{n c}\right)$ & $\rho_{d}^{n c}$ \\
Total & 1 & $\rho_{d}^{n c}$ \\
\hline
\end{tabular}

$\emptyset_{n c}$ porosity of the non-carbonated paste.

$\rho_{d}^{n c}$ dry density of the non-carbonated paste.

The molar volume of silica gel was similar to that obtained for the CS-H paste (37 versus $40 \mathrm{~cm}^{3} / \mathrm{mol}$ ). The molar mass was however somewhat different (71 versus $93 \mathrm{~g} / \mathrm{mol}$ ). It should be noted that the values obtained using the results from the $\mathrm{C}_{3} \mathrm{~S}$ paste were much more uncertain than those of the C-S-H paste $(\mathrm{C} / \mathrm{S}=1.4)$, mainly because of the remaining $\mathrm{CH}$ and $\mathrm{C}-\mathrm{S}-\mathrm{H}$, which made it difficult to accurately estimate the volume and mass of the silica gel.

$V_{m}(S-H)=\frac{\left(1-\varnothing_{c}\right)-[C H]_{r} V_{m}(C H)-[C a l] V_{m}(C a l)-[C-S-H]_{r} V_{m}(C-S-H)}{[C-S-H]_{0}-[C-S-H]_{r}} \approx 37 \mathrm{~cm}^{3} / \mathrm{mol}$

$M_{m}(S-H)=\frac{\rho_{d}^{c}-[C H]_{r} M_{m}(\mathrm{CH})-[\mathrm{Cal}] M_{m}(\mathrm{Cal})-[\mathrm{C}-\mathrm{S}-H]_{r} M_{m}(\mathrm{C}-\mathrm{S}-\mathrm{H})}{[\mathrm{C}-\mathrm{S}-\mathrm{H}]_{0}-[\mathrm{C}-\mathrm{S}-\mathrm{H}]_{r}} \approx 71 \mathrm{~g} / \mathrm{mol}$ 


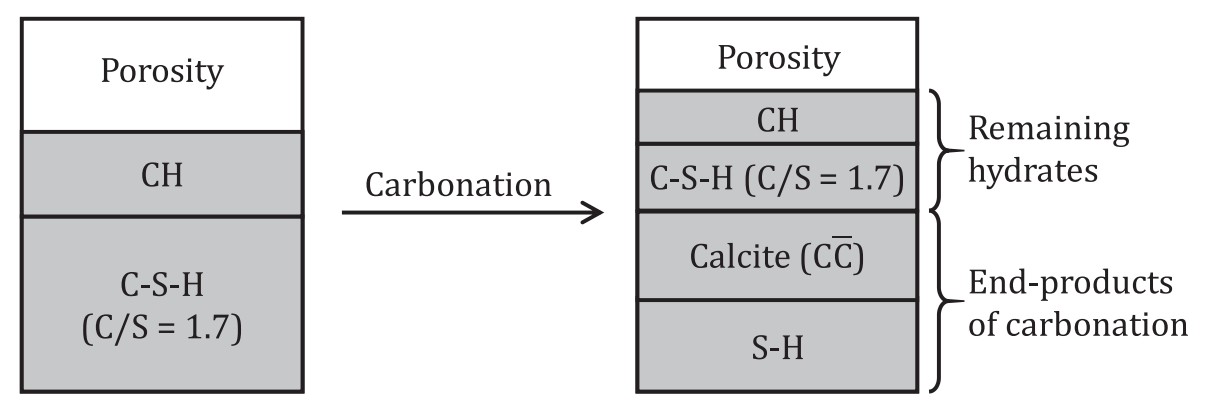

Non carbonated paste

Partially carbonated paste

Fig. 17. Effect of the carbonation on the $\mathrm{C}_{3} \mathrm{~S}$ paste, the carbonation products and partially carbonated hydrated coexist.

Table 8

Volume and mass of the different phases in the non-carbonated $\mathrm{C}_{3} \mathrm{~S}$ paste $(\mathrm{C} / \mathrm{S}=$ 3.0).

\begin{tabular}{lll}
\hline Phase & Volume & Mass \\
\hline Voids & $\emptyset_{\text {nc }}$ & 0 \\
CH & {$[\mathrm{CH}]_{0} V_{m}(\mathrm{CH})$} & {$[\mathrm{CH}]_{0} M_{m}(\mathrm{CH})$} \\
C-S-H & $\left(1-\emptyset_{n c}\right)-[\mathrm{CH}]_{0} V_{m}(\mathrm{CH})$ & $\rho_{d}^{n c}-[\mathrm{CH}]_{0} \mathrm{M}_{\mathrm{m}}(\mathrm{CH})$ \\
Total & 1 & $\rho_{d}^{n c}$ \\
\hline
\end{tabular}

$[\mathrm{CH}]_{0}$ concentration of portlandite in the non-carbonated paste.

$V_{m}(\mathrm{CH})$ molar volume of portlandite $\left(33 \mathrm{~cm}^{3} / \mathrm{mol}\right)$.

$M_{m}(\mathrm{CH})$ molar mass of portlandite $(74.1 \mathrm{~g} / \mathrm{mol})$.

Table 9

Volume and mass of the different phases in the carbonated $C_{3}$ S paste $(C / S=3.0)$.

\begin{tabular}{lll}
\hline Phase & Volume & Mass \\
\hline Voids & $\emptyset_{\mathrm{c}}$ & 0 \\
CH & {$[\mathrm{CH}]_{r} V_{m}(\mathrm{CH})$} & {$[\mathrm{CH}]_{\mathrm{r}} M_{m}(\mathrm{CH})$} \\
C-S-H & {$[\mathrm{C}-\mathrm{S}-\mathrm{H}]_{\mathrm{r}} V_{m}(\mathrm{C}-\mathrm{S}-\mathrm{H})$} & {$[\mathrm{C}-\mathrm{S}-\mathrm{H}]_{\mathrm{r}} M_{m}(\mathrm{C}-\mathrm{S}-\mathrm{H})$} \\
Calcite & {$[\mathrm{Cal}] V_{m}(\mathrm{Cal})$} & {$[\mathrm{Cal}] M_{m}(\mathrm{Cal})$} \\
S-H & $\left(1-\emptyset_{c}\right)-V_{m}(\mathrm{CH})-V_{m}(\mathrm{Cal})-V_{m}(\mathrm{C}-\mathrm{S}-\mathrm{H})$ & $\rho_{d}^{c} M_{m}(\mathrm{CH})-M_{m}(\mathrm{Cal})-M_{m}(\mathrm{C}-\mathrm{S}-\mathrm{H})$ \\
Total & 1 & $\rho_{d}^{c}$ \\
\hline
\end{tabular}

$[\mathrm{CH}]_{\mathrm{r}}$ concentration of the remaining portlandite in the carbonated paste. $[\mathrm{C}-\mathrm{S}-\mathrm{H}]_{\mathrm{r}}$ concentration of the remaining C-S-H in the carbonated paste.

[Cal] concentration of calcite in the carbonated paste

$V_{m}(\mathrm{Cal})$ molar volume of calcite $\left(35 \mathrm{~cm}^{3} / \mathrm{mol}\right)$

$M_{m}(\mathrm{Cal})$ molar mass of calcite $(100.1 \mathrm{~g} / \mathrm{mol})$.

Using the values computed above, it is easy to evaluate the change in volume induced by the decalcification of the C-S-H, $\Delta V_{d}(C-S-H)$ :

$\Delta V_{d}(C-S-H)=V_{m}(S-H)-V_{m}(C-S-H) \approx 40-69=-29 \mathrm{~cm}^{3} / \mathrm{mol}$

Because one mole of $\mathrm{S}-\mathrm{H}$ is less voluminous than one mole of $\mathrm{C}-\mathrm{S}-\mathrm{H}$, the decalcification of the C-S-H leads to a significant reduction in the solid volume (about $29 \mathrm{~cm}^{3} / \mathrm{mol}$ ). This is consistent with the conclusions of Chen et al. [107] and with the results of Morandeau et al. [97,108] who found that $\Delta V_{d}(C-S-H)$ was between 20 and $40 \mathrm{~cm}^{3} / \mathrm{mol}$. Nonetheless, the precipitation of calcium carbonate also plays a significant role in changes in volume during carbonation of C-S-H (E- 12). It is evident that the reduction of solid volume generated by the decalcification of C-S-H is compensated by the precipitation of calcium carbonate

Table 10

Change in solid volume $\left(\mathrm{cm}^{3} / \mathrm{mol}\right)$ induced by the carbonation of C-S-H, according to Eq. (16).

\begin{tabular}{lllll}
\hline$\Delta V_{c}(C-S-H)$ & Aragonite & Calcite & Vaterite & Unit \\
\hline $\mathrm{C} / \mathrm{S}=1.4$ & +18.6 & +20.0 & +24.4 & $\mathrm{~cm}^{3} / \mathrm{mol}$ \\
$\mathrm{C} / \mathrm{S}=1.7$ & +28.8 & +30.5 & +35.4 & $\mathrm{~cm}^{3} / \mathrm{mol}$ \\
\hline
\end{tabular}

(Table 10), resulting in the reduction of total porosity. Indeed, the change in volume depends on the calcium carbonate polymorph that is precipitated and on the $\mathrm{C} / \mathrm{S}$ ratio of the $\mathrm{C}-\mathrm{S}-\mathrm{H}$. However, the increase in solid volume induced by the carbonation of C-S-H is expected to lie between 19 and $35 \mathrm{~cm}^{3} / \mathrm{mol}$. This means that the carbonation of high C/ $\mathrm{S}$ C-S-H (between 1.4 and 1.7) cannot be expected to generate an increase in porosity as was observed by $\mathrm{Wu}$ and $\mathrm{Ye}$ [28] and Shah et al. [109].

$\Delta V_{c}(C-S-H)=V_{m}(S-H)+\left(\frac{C}{S}\right) V_{m}(C \bar{C})-V_{m}(C-S-H)$

The change in solid volume induced by the carbonation of C-S-H is one order of magnitude greater than that of portlandite (which ranges between 1 and $5 \mathrm{~cm}^{3} / \mathrm{mol}$ ). C-S-H is then likely to contribute more to porosity reduction than portlandite. This was confirmed in the case of the $\mathrm{C}_{3} \mathrm{~S}$ paste for which the change in solid volume induced by the carbonation of both $\mathrm{CH}$ and $\mathrm{C}-\mathrm{S}-\mathrm{H}$ was evaluated (calcite was assumed to be the only calcium carbonate polymorph precipitated):

$$
\begin{aligned}
& \begin{aligned}
\Delta V_{C-S-H} & =40 \%[\mathrm{C}-S-H]_{0} \Delta V_{c}(C-S-H)=0.4 \times 5.6 \times 30.5 \\
& \approx+68 \mathrm{~cm}^{3} / \mathrm{L} \text { of paste } \\
\Delta V_{C H}= & 75 \%[\mathrm{CH}]_{0}\left(V_{m}(\mathrm{Cal})-V_{m}(\mathrm{CH})\right)=0.75 \times 7.3 \times 2 \\
\approx & +11 \mathrm{~cm} 3 / \mathrm{L} \text { of paste }
\end{aligned}
\end{aligned}
$$

The change in porosity in the $\mathrm{C}_{3} \mathrm{~S}$ paste was mostly due to C-S-H,

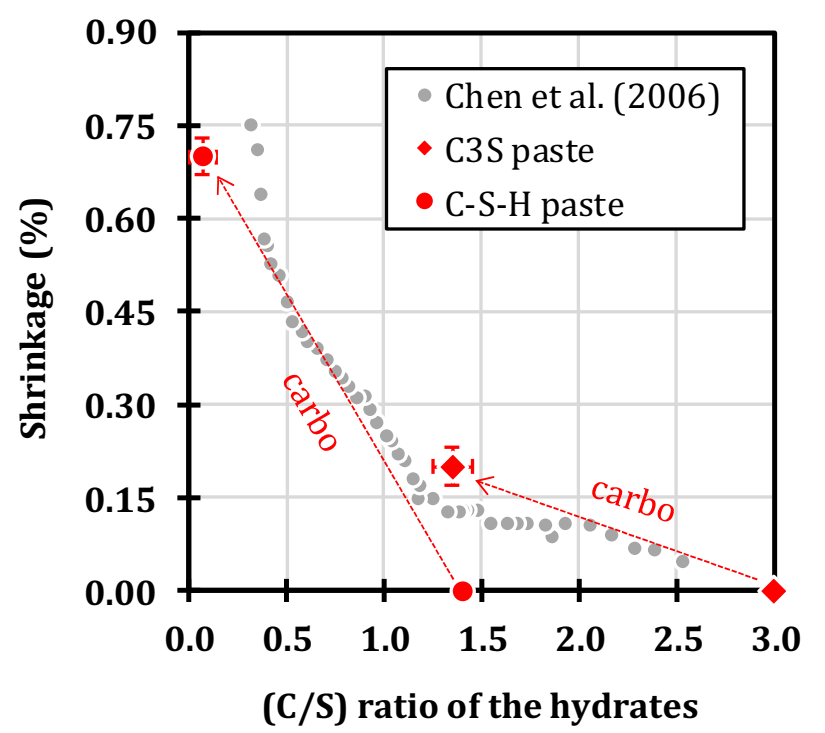

Fig. 18. Comparison of the carbonation shrinkage results obtained in this study with the $\mathrm{NH}_{4} \mathrm{NO}_{3}$ degradation data of Chen et al. [107]. 
even though the proportion of $\mathrm{CH}$ that was carbonated was greater than that of C-S-H. This was consistent with the conclusions of other studies $[97,108,110]$. These data might prove useful in evaluating the impact of carbonation on transport properties [111-113]. It should be noted, however, that this is only relevant in the presence of portlandite. Indeed, in the absence of portlandite, cracking is expected to prevail and make porosity reduction negligible in terms of transport $[35,100]$ (cf. Section 5.3).

\subsection{Carbonation shrinkage}

The carbonation shrinkage of the C-S-H paste (which was devoid of portlandite) was more pronounced intense than that of the $\mathrm{C}_{3} \mathrm{~S}$ paste including portlandite (Fig. 18 \& Table 5). This strongly suggested that the dissolution of portlandite was not responsible for carbonation shrinkage, which contradicts Powers' hypothesis [114]. Rather, carbonation shrinkage was related to C-S-H alteration as it was inferred by Sereda et al. [30,31]. With that in mind, the carbonation shrinkage values (Table 5) were compared to those obtained by Chen et al. [107] who studied the shrinkage of $\mathrm{C}_{3} \mathrm{~S}$ samples exposed to accelerated degradation (using $\mathrm{NH}_{4} \mathrm{NO}_{3}$ ). Chen et al. [107] concluded that shrinkage was related to the decalcification of C-S-H and subsequent polymerisation of silica chains. It is obvious from Fig. 18 that the carbonation shrinkage values obtained here are consistent with those obtained by Chen et al. [107].

However, because of the presence of portlandite, the $\mathrm{C} / \mathrm{S}$ ratio of the $\mathrm{C}_{3} \mathrm{~S}$ paste could not be compared directly to that of the $\mathrm{C}-\mathrm{S}$-H paste (free of portlandite). This shortcoming was easily overcome by computing the change in C-S-H C/S ratio. Here we made the choice to characterise the decalcification level of the C-S-H using:

$\Delta(C / S)=\frac{(C / S)(t)-(C / S)_{0}}{(C / S)_{0}}$

where $(C / S)(t)$ is the C/S ratio of the C-S-H at time $t$ and $(C / S)_{0}$ the $\mathrm{C} / \mathrm{S}$ ratio of the unaltered C-S-H. The expression $\Delta(C / S)=0 \%$ means that the C-S-H are unaltered, whereas $\Delta(C / S)=100 \%$ means that the C-S-H are completely degraded. The values of $\Delta(C / S)$ could be easily computed for the tests of Chen et al. [107] because portlandite was completely dissolved when the $\mathrm{C} / \mathrm{S}$ ratio of the solid $(\mathrm{CH}+\mathrm{C}-\mathrm{S}-\mathrm{H})$ reached 1.4 (see Section 4.1 of [107]). The shrinkage values were then plotted against the decalcification level $\Delta(C / S)$ in Fig. 19. Despite some inevitable discrepancy, the results from Chen et al. and those from this study

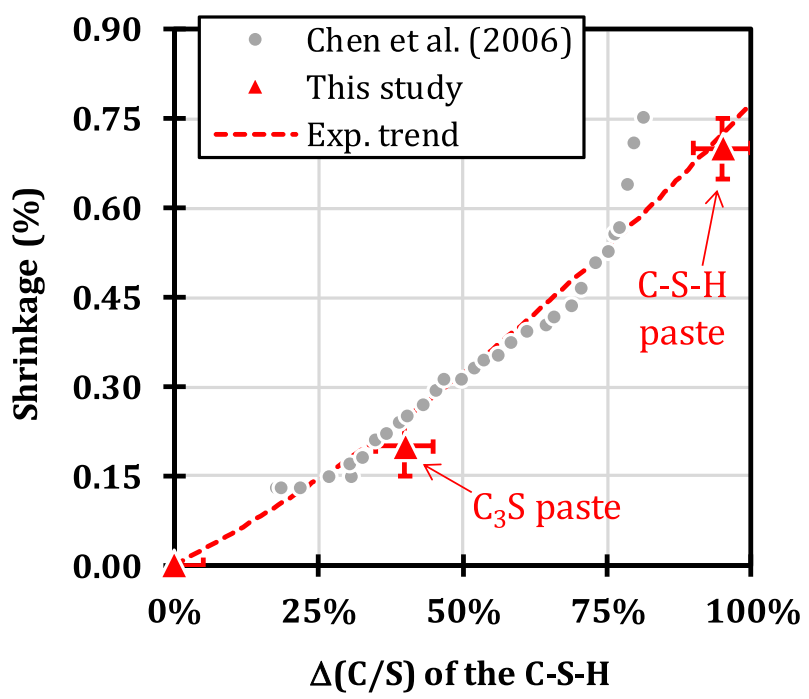

Fig. 19. Carbonation shrinkage versus decalcification level $\Delta(\mathrm{C} / \mathrm{S})$ of high $\mathrm{C} / \mathrm{S}$ C-S-H. describe a common trend: the shrinkage increases with the decalcification level of the C-S-H. This unambiguously confirms that the shrinkage generated by carbonation is due to the decalcification of C-S-H and polymerisation of the silica chains as it is the case for decalcification [107]. At a first glance, it may be surprising that carbonation and decalcification generate similar shrinkage because they are both quite different. Carbonation induces $\mathrm{CaCO}_{3}$ precipitation, densification of the matrix and an increase in mechanical properties [115-118], whereas decalcification is responsible for Ca leaching, porosity increase and a significant decrease in mechanical properties [119-123]. What really actually matters is that carbonation and degradation both induce significant decalcification and shrinkage of the C-S-H matrix that embeds all the other minerals. It is the shrinkage of the matrix that induces the shrinkage of the cementitious material.

The following 2nd order polynomial was proposed to fit the data:

$\varepsilon^{c}=0.264 \Delta^{2}(C / S)+0.513 \Delta(C / S)$

This simple approach allows for estimation of the shrinkage generated by the decalcification of high C/S C-S-H (between 1.4 and 1.7). Please note that this function is not expected to be valid for lower $\mathrm{C} / \mathrm{S}$ values. More results would be greatly appreciated to verify this.

\subsection{The role of portandite}

The results presented here stress the influence of the mineralogical composition on atmospheric carbonation. The C-S-H paste appeared to be completely carbonated (no remaining C-S-H after carbonation), and the porosity was strongly reduced due to $\mathrm{CaCO}_{3}$ precipitation, but the $\mathrm{C}$ $\mathrm{S}-\mathrm{H}$ decalcification and the silica chain polymerisation generated significant shrinkage and cracking that resulted in the increase in diffusion coefficient. Conversely, the $\mathrm{C}_{3} \mathrm{~S}$ paste carbonation gave quite different results: carbonation was not complete (portlandite and C-S-H remained in significant amounts in the carbonated zone), the porosity was reduced but less so than for the C-S-H paste. Furthermore, only a few cracks could be observed in the carbonated zone and the diffusion coefficient was reduced by carbonation.

The only reason why the $\mathrm{C}_{3} \mathrm{~S}$ paste suffered less from carbonation compared to the C-S-H paste was due to the presence of portlandite. It must be recalled that the reaction between $\mathrm{Ca}^{2+}$ ions and (dissolved) $\mathrm{CO}_{2}$ in the pore solution tends to decrease $\mathrm{Ca}^{2+}$ concentration, and thus portlandite dissolves to maintain equilibrium. In the C-S-H paste in which portlandite was absent, Ca was withdrawn from the C-S-H, leading to their complete decalcification. This generated significant decalcification shrinkage and cracking and the gas diffusion coefficient was increased, despite the strong reduction in porosity. In the $\mathrm{C}_{3} \mathrm{~S}$ paste, portlandite contributed to protecting the $\mathrm{C}-\mathrm{S}-\mathrm{H}$ from decalcification and reducing the shrinkage induced by carbonation. As a consequence, portlandite did provide some kind of mechanical protection to the $\mathrm{C}_{3} \mathrm{~S}$ paste because carbonation-induced cracking remained limited and the reduction in porosity led to a reduction in the gas diffusion coefficient.

By protecting the $\mathrm{C}-\mathrm{S}-\mathrm{H}$, portlandite also contributed to protecting the $\mathrm{C}_{3} \mathrm{~S}$ paste from carbonation. Because carbonation is (partly) driven by $\mathrm{CO}_{2}$ diffusion through the carbonated layer (see Eq. (2)), the reduction in diffusion coefficient induced by carbonation enabled low values $\left(2.7-5.2 \times 10^{-8} \mathrm{~m}^{2} / \mathrm{s}\right)$ to be obtained that helped limit the carbonation rate of the $\mathrm{C}_{3} \mathrm{~S}$ paste. Conversely, the strong increase in diffusion coefficient of the C-S-H paste (which was induced by carbonation shrinkage and cracking) yielded a higher value of the diffusion coefficient $(\approx 20.0$ $\times 10^{-8} \mathrm{~m}^{2} / \mathrm{s}$ ) and finally a higher carbonation rate. It should be noted that despite a strong difference in their initial Ca content, the carbonation of the two pastes appeared to yield similar amounts of $\mathrm{CaCO}_{3}(9.8$ and $9.3 \mathrm{~mol} / \mathrm{L}$ of paste for the $\mathrm{C}-\mathrm{S}-\mathrm{H}$ and $\mathrm{C}_{3} \mathrm{~S}$ pastes respectively, see Table 3). Thus, the difference in carbonation rates was expected to be mainly due to the difference in diffusion coefficient. This was consistent with the conclusions of Dutzer et al. [100]. 


\section{Conclusion}

The use of two different model pastes $\left(\mathrm{a}_{3} \mathrm{~S}\right.$ paste and a C-S-H paste with $\mathrm{C} / \mathrm{S}=1.4$ devoid of portlandite) made it possible to investigate the mechanisms and consequences of atmospheric carbonation. Firstly, and owing to the simplicity of the pastes' mineralogical assemblage, the molar volumes of C-S-H and silica gel (the end-product of C-S-H decalcification) could be estimated. This allowed for evaluation of the change in solid volume induced by the decalcification and the carbonation of C$\mathrm{S}$-H. A comparison between the change in volume induced by the carbonation of portlandite indicates that C-S-H is more than likely to be the main contributor in change in porosity.

Secondly, the shrinkage induced by carbonation was measured and compared with the $\mathrm{NH}_{4} \mathrm{NO}_{3}$ leaching results of Chen et al. [107]. The comparison was satisfactory, which confirmed that carbonation shrinkage was associated with the decalcification of C-S-H and polymerisation of the silica chains.

Thirdly, all the results highlight the protective role of portlandite. From a chemical point of view, portlandite has long been known to act as a Ca-buffer that dissolves in the first instance to maintain the Caconcentration in the pore solution. This helps in limiting the carbonation rate, protecting the $\mathrm{C}-\mathrm{S}-\mathrm{H}$ from decalcification and then limiting subsequent cracking. In conclusion, the presence of portlandite does indeed provide indirect protection from cracking induced by carbonation.

\section{Data availability}

The data that supports the results presented in this article is not meant to be broadly disseminated but it can be provided by the authors upon reasonable request.

\section{CRediT authorship contribution statement}

E. KANGNI-FOLI: Investigation, Resources, Visualization, Writingoriginal draft.

S. POYET: Conceptualization, Methodology, Validation, Data curation, Supervision, Writing-review \& editing.

P. LE BESCOP: Methodology, Validation, Data curation.

T. CHARPENTIER: Formal analysis, Validation, Data Curation, Writing-review \& editing.

F. BERNACHY-BARBE: Formal analysis, Methodology, Writingreview \& editing.

A. DAUZERES: Conceptualization, Funding acquisition, Supervision, Writing-review \& editing.

E. L'HÔPITAL: Formal analysis, Methodology, Writing-review \& editing.

J.-B. D'ESPINOSE DE LACAILLERIE: Supervision, Formal analysis, Writing-review \& editing.

\section{Declaration of competing interest}

No potential conflict of interest was reported by the authors.

\section{Acknowledgments}

The authors gratefully acknowledge financial support from CEA (grant DEN 4425) and IRSN (grant DAFCJ/SJ/LS 20301). The authors would like to thank Céline Cau Dit Coumes (CEA Marcoule, France) and Barbara Lothenbach (EMPA, Switzerland) for helpful comments.

\section{References}

[1] H.F.W. Taylor, Cement Chemistry, 2nd ed., Academic Press, London (UK), 1990 https://doi.org/10.1016/S0958-9465(98)00023-7.

[2] W.F. Cole, B. Kroone, Carbonate minerals in hydrated Portland cement, Nature. 184 (1959) BA57.
[3] W.F. Cole, B. Kroone, Carbon dioxide in hydrated Portland cement, J. Am. Concr. Inst. 56 (1960) 1275-1296.

[4] L. Bertolini, B. Elsener, P. Pedeferri, R. Polder, Corrosion of Steel in Concrete Prevention, Diagnosis, Repair, Wiley, 2004.

[5] R. Neves, F.A. Branco, J. de Brito, A method for the use of accelerated carbonation tests in durability design, Constr. Build. Mater. 36 (2012) 585-591, https://doi.org/10.1016/j.conbuildmat.2012.06.028.

[6] M. Thiery, G. Villain, P. Dangla, G. Platret, Investigation of the carbonation front shape on cementitious materials: effects of the chemical kinetics, Cem. Concr. Res. 37 (2007) 1047-1058, https://doi.org/10.1016/j.cemconres.2007.04.002.

[7] B. Bary, A. Sellier, Coupled moisture-carbon dioxide-calcium transfer model for carbonation of concrete, Cem. Concr. Res. 34 (2004) 1859-1872, https://doi.org/ 10.1016/j.cemconres.2004.01.025.

[8] A.V. Saetta, B.A. Schrefler, R.V. Vitaliani, 2-D model for carbonation and moisture/heat flow in porous materials, Cem. Concr. Res. 25 (1995) 1703-1712, https://doi.org/10.1016/0008-8846(95)00166-2.

[9] A.V. Saetta, R.V. Vitaliani, Experimental investigation and numerical modeling of carbonation process in reinforced concrete structures part I: theoretical formulation, Cem. Concr. Res. 34 (2004) 571-579, https://doi.org/10.1016/j. cemconres.2003.09.009.

[10] M. Te Liang, W. Qu, C.H. Liang, S.M. Lin, Mathematical modeling and applications for concrete carbonation, J. Mar. Sci. Technol. 11 (2003) 20-33.

[11] A. Silva, R. Neves, J. De Brito, Statistical modelling of carbonation in reinforced concrete, Cem. Concr. Compos. 50 (2014) 73-81, https://doi.org/10.1016/j. cemconcomp.2013.12.001.

[12] N. Seigneur, É. Kangni-Foli, V. Lagneau, A. Dauzères, S. Poyet, P. Le Bescop, E. L'Hôpital, J.B. d'Espinose de Lacaillerie, Understanding the effects of the atmospheric carbonation of cementitious materials using reactive transport modelling, Cem. Concr. Res. 130 (2020) 105966, https://doi.org/10.1016/j. cemconres.2019.105966.

[13] R.A. Olson, H.M. Jennings, Estimation of C-S-H content in a blended cement paste using water adsorption, Cem. Concr. Res. 31 (2001) 351-356, https://doi.org/ 10.1016/S0008-8846(01)00454-9.

[14] D.P. Bentz, Guide to Using CEMHYD3D: A Three-dimensional Cement Hydration and Microstructure Development Modelling Package, 2005.

[15] L. Barcelo, Chemical shrinkage, in: Early Age Crack. Cem. Syst. - RILEM Rep. 025, RILEM, 2003, pp. 21-25.

[16] D. Herfort, B. Lothenbach, Ternary phase diagrams applied to hydrated cement, in: K. Scrivener, R. Snellings, B. Lothenbach (Eds.), A Pract. Guid. to Microstruct. Anal. Cem. Mater, CRC Press, Boca Raton (USA), 2016, pp. 485-502.

[17] Z.P. Bažant, S. Rahimi-Aghdam, Century-long durability of concrete structures: Expansiveness of hydration and chemo-mechanics of autogenous shrinkage and swelling, in: G. Meschke, B. Pichler, J.G. Rots (Eds.), Comput. Model. Concr. Struct. - Proc. Conf. EURO-C 2018, Taylor \& Francis, Bad Hofgastein (Austria), 2018, pp. 15-23, https://doi.org/10.1201/9781315182964-2.

[18] P.D. Tennis, H.M. Jennings, A model for two types of calcium silicate hydrate in the microstructure of Portland cement pastes, Cem. Concr. Res. 30 (2000) 855-863.

[19] S. Bishnoi, K.L. Scrivener, $\mu$ ic: A new platform for modelling the hydration of cements, Cem. Concr. Res. 39 (2009) 266-274, https://doi.org/10.1016/j. cemconres.2008.12.002.

[20] P. Blanc, X. Bourbon, A. Lassin, E.C. Gaucher, Chemical model for cement-based materials: temperature dependence of thermodynamic functions for nanocrystalline and crystalline C-S-H phases, Cem. Concr. Res. 40 (2010) 851-866, https://doi.org/10.1016/j.cemconres.2009.12.004.

[21] B. Lothenbach, T. Matschei, G. Möschner, F.P. Glasser, Thermodynamic modelling of the effect of temperature on the hydration and porosity of Portland cement, Cem. Concr. Res. 38 (2008) 1-18, https://doi.org/10.1016/j. cemconres.2007.08.017.

[22] B. Lothenbach, D.A. Kulik, T. Matschei, M. Balonis, L. Baquerizo, B. Dilnesa, G. D. Miron, R.J. Myers, Cemdata18: a chemical thermodynamic database for hydrated Portland cements and alkali-activated materials, Cem. Concr. Res. 115 (2019) 472-506, https://doi.org/10.1016/j.cemconres.2018.04.018.

[23] R.J.-M. Pellenq, A. Kushima, R. Shahsavari, K.J. Van Vliet, M.J. Buehler, S. Yip, F.-J. Ulm, A realistic molecular model of cement hydrates, Proc. Natl. Acad. Sci. U. S. A. 106 (2009) 16102-16107, https://doi.org/10.1073/pnas.0902180106.

[24] A.J. Allen, J.J. Thomas, H.M. Jennings, Composition and density of nanoscale calcium-silicate-hydrate in cement, Nat. Mater. 6 (2007) 311-316, https://doi. org/10.1038/nmat1871.

[25] H.M. Jennings, Refinements to colloid model of C-S-H in cement: CM-II, Cem. Concr. Res. 38 (2008) 275-289, https://doi.org/10.1016/j. cemconres.2007.10.006.

[26] D.A. Kulik, Aqueous solubility diagrams for cementitious waste stabilization systems: II, end-member stoichiometries of ideal calcium silicate hydrate solid solutions, J. Am. Ceram. Soc. 84 (2001) 3017-3026.

[27] D.A. Kulik, Improving the structural consistency of C-S-H solid solution thermodynamic models, Cem. Concr. Res. 41 (2011) 477-495, https://doi.org/ 10.1016/j.cemconres.2011.01.012.

[28] B. Wu, G. Ye, Development of porosity of cement paste blended with supplementary cementitious materials after carbonation, Constr. Build. Mater. 145 (2017) 52-61, https://doi.org/10.1016/j.conbuildmat.2017.03.176.

[29] G.J. Verbeck, Carbonation of hydrated Portland cement, ASTM Spec. Tech. Publ. 205 (1958) 17-36.

[30] K. Kamimura, P.J. Sereda, E.G. Swenson, Changes in weight and dimensions in the drying and carbonation of Portland cement mortars, Mag. Concr. Res. 17 (1965) 5-14. 
[31] E.G. Swenson, P.J. Sereda, Mechanism of the carbonation shrinkage of lime and hydrated cement, J. Appl. Chem. 18 (1968) 111-117.

[32] Y.F. Houst, Carbonation shrinkage of hydrated cement paste, in: V.M. Malhotra (Ed.), 4th CANMET/ACI Int. Conf. Durab. Concr, ACI, Sydney (Australia), 1997, pp. 481-491.

[33] Y. Suda, J. Tomiyama, T. Saito, T. Saeki, Effect of relative humidity on carbonation shrinkage and hydration product of cement paste (in japanese), Cement Sci. Concr. Technol. 73 (2019) 71-78, https://doi.org/10.14250/ cement.73.71.

[34] P.H.R. Borges, J.O. Costa, N.B. Milestone, C.J. Lynsdale, R.E. Streatfield, Carbonation of $\mathrm{CH}$ and C-S-H in composite cement pastes containing high amounts of BFS, Cem. Concr. Res. 40 (2010) 284-292, https://doi.org/10.1016/j cemconres. 2009.10.020.

[35] M. Auroy, S. Poyet, P. Le Bescop, J.M. Torrenti, T. Charpentier, M. Moskura, $\mathrm{X}$. Bourbon, Impact of carbonation on unsaturated water transport properties of cement-based materials, Cem. Concr. Res. 74 (2015) 44-58, https://doi.org/ 10.1016/j.cemconres.2015.04.002.

[36] J. Han, W. Sun, G. Pan, W. Caihui, Monitoring the evolution of accelerated carbonation of hardened cement pastes by X-ray computed tomography, J. Mater Civ. Eng. 25 (2013) 347-354.

[37] K. Wan, Q. Xu, Y. Wang, G. Pan, 3D spatial distribution of the calcium carbonate caused by carbonation of cement paste, Cem. Concr. Compos. 45 (2014) 255-263, https://doi.org/10.1016/j.cemconcomp.2013.10.011.

[38] P. Halamickova, R.J. Detwiler, Water permeability and chloride ion diffusion in Portland cement mortars: relationship to sand content and critical pore diameter Cem. Concr. Res. 25 (1995) 790-802, https://doi.org/10.1016/0008-8846(95) 00069-O.

[39] Y.F. Houst, F.H. Wittmann, Influence of porosity and water content on the diffusivity of $\mathrm{CO}_{2}$ and $\mathrm{O}_{2}$ through hydrated cement paste, Cem. Concr. Res. 24 (1994) 1165-1176, https://doi.org/10.1016/0008-8846(94)90040-X.

[40] F. Frizon, C. Gallé, Diffusive and convective transport of inert gas through cement pastes: influence of microstructure and water, J. Porous Media. 12 (2009) 221-237, https://doi.org/10.1615/JPorMedia.v12.i3.30.

[41] M. Boumaaza, P. Turcry, B. Huet, A. Ait-mokhtar, Influence of carbonation on the microstructure and the gas diffusivity of hardened cement pastes, Constr. Build. Mater. 253 (2020) 119227, https://doi.org/10.1016/j. conbuildmat.2020.119227.

[42] É. Kangni-Foli, S. Poyet, P. Le Bescop, T. Charpentier, F. Bernarchy-Barbé, A. Dauzères, E. L'Hôpital, M. Neji, J.B. d'Espinose de Lacaillerie, Model synthetic pastes for low pH cements, Cem. Concr. Res. 136 (2020) 106168.

[43] I. Klur, B. Pollet, J. Virlet, A. Nonat, C-S-H structure evolution with calcium content by multinuclear NMR, in: Nucl. Magn. Reson. Spectrosc. Cem. Mater, Springer Berlin Heidelberg, Berlin, Heidelberg, 1998, pp. 119-141, https://doi. org/10.1007/978-3-642-80432-8_8.

[44] K. Garbev, G. Beuchle, M. Bornefeld, L. Black, P. Stemmermann, Cell dimensions and composition of nanocrystalline calcium silicate hydrate solid solutions. Part 1: synchrotron-based x-ray diffraction, J. Am. Ceram. Soc. 91 (2008) 3005-3014, https://doi.org/10.1111/j.1551-2916.2008.02484.x.

[45] G. Renaudin, J. Russias, F. Leroux, F. Frizon, C. Cau-dit-Coumes, Structural characterization of C-S-H and C-A-S-H samples-part I: long-range order investigated by Rietveld analyses, J. Solid State Chem. 182 (2009) 3312-3319, https://doi.org/10.1016/j.jssc.2009.09.026.

[46] Y. Suda, T. Saeki, T. Saito, Relation between chemical composition and physical properties of C-S-H generated from cementitious materials, J. Adv. Concr. Technol. 13 (2015) 275-290, https://doi.org/10.3151/jact.13.275.

[47] E. Tajuelo Rodriguez, K. Garbev, D. Merz, L. Black, I.G. Richardson, Thermal stability of C-S-H phases and applicability of Richardson and Groves' and Richardson C-(A)-S-H(I) models to synthetic C-S-H, Cem. Concr. Res. 93 (2017) 45-56, https://doi.org/10.1016/j.cemconres.2016.12.005.

[48] W. Kunther, S. Ferreiro, J. Skibsted, Influence of the $\mathrm{Ca} / \mathrm{Si}$ ratio on the compressive strength of cementitious calcium-silicate-hydrate binders, J. Mater Chem. A 5 (2017) 17401-17412, https://doi.org/10.1039/c7ta06104h.

[49] C. Roosz, P. Vieillard, P. Blanc, S. Gaboreau, H. Gailhanou, D. Braithwaite, V. Montouillout, R. Denoyel, P. Henocq, B. Madé, Thermodynamic properties of C-S-H, C-A-S-H and M-S-H phases: results from direct measurements and predictive modelling, Appl. Geochem. 92 (2018) 140-156, https://doi.org/ 10.1016/j.apgeochem.2018.03.004.

[50] G. Quercia, G. Hüsken, H.J.H. Brouwers, Water demand of amorphous nano silica and its impact on the workability of cement paste, Cem. Concr. Res. 42 (2012) 344-357, https://doi.org/10.1016/j.cemconres.2011.10.008.

[51] S. Abd.El.Aleem, M. Heikal, W.M. Morsi, Hydration characteristic, thermal expansion and microstructure of cement containing nano-silica, Constr. Build. Mater. 59 (2014) 151-160, https://doi.org/10.1016/j.conbuildmat.2014.02.039.

[52] B. Lothenbach, P. Durdzinski, K. De Weerdt, Thermogravimetric analysis, in: K. Scrivener, R. Snellings, B. Lothenbach (Eds.), A Pract. Guid. to Microstruct. Anal. Cem. Mater, CRC Press, Boca Raton (USA), 2016, pp. 177-211.

[53] L. Greenspan, Humidity fixed points of binary saturated aqueous solutions, J. Res. Natl. Bur. Stand. Sect. A Phys. Chem. 81A (1977) 89-96, https://doi.org/ 10.6028/jres.081A.011.

[54] E. Drouet, S. Poyet, P. Le Bescop, J.-M. Torrenti, X. Bourbon, Carbonation of hardened cement pastes: influence of temperature, Cem. Concr. Res. 115 (2019) 445-459, https://doi.org/10.1016/J.CEMCONRES.2018.09.019.

[55] M. Auroy, S. Poyet, P. Le Bescop, J.-M. Torrenti, T. Charpentier, M. Moskura, X. Bourbon, Comparison between natural and accelerated carbonation $\left(3 \% \mathrm{CO}_{2}\right)$ : impact on mineralogy, microstructure, water retention and cracking, Cem. Concr. Res. 109 (2018) 64-80, https://doi.org/10.1016/j.cemconres.2018.04.012.
[56] G. Le Saoût, T. Füllmann, V. Kocaba, K.L. Scrivener, Quantitative study of cementitous materials by $\mathrm{x}$-ray diffraction - Rietveld analysis using an external standard, in: J.J. Beaudoin, J.M. Makar, L. Raki (Eds.), Proc. 12th Int. Congr. Chem. Cem, Cement Association of Canada, Montréal (Canada), 2007, 12p.

[57] R. Snellings, X-ray powder diffraction applied to cement, in: A Pract. Guid. to Microstruct. Anal. Cem. Mater, 2016, pp. 107-176.

[58] I.G. Richardson, Model structures for C-(A)-S-H(I), Acta Crystallogr. Sect. B: Struct. Sci. Cryst. Eng. Mater. 70 (2014) 903-923, https://doi.org/10.1107/ S2052520614021982.

[59] G. Villain, M. Thiery, G. Platret, Measurement methods of carbonation profiles in concrete: thermogravimetry, chemical analysis and gammadensimetry, Cem. Concr. Res. 37 (2007) 1182-1192, https://doi.org/10.1016/j. cemconres.2007.04.015.

[60] E. Lippmaa, M. Magi, A. Samoson, G. Engelhardt, A.-R. Grimmer, Structural studies of silicates by solid-state, J. Am. Chem. Soc. Am. 102 (1980) 4889-4893.

[61] J.R. Kirkpatrick, Nuclear magnetic resonance spectroscopy, in: V.

S. Ramachandran, J.J. Beaudouin (Eds.), Handb. Anal. Tech. Concr, Noyes Publications, Park Ridge NJ (USA), 2001, pp. 205-230, https://doi.org/10.1007/ 978-1-62703-176-9_26.

[62] J. Skibsted, High-resolution solid-state nuclear magnetic resonance spectroscopy of Portland cement-based systems, in: K.L. Scrivener, R. Snellings, B. Lothenbach (Eds.), A Pract. Guid. to Microstruct. Anal. Cem. Mater, Taylor \& Francis, Boca Raton (USA), 2016, pp. 214-286.

[63] S. Merlino, E. Bonaccorsi, T. Armbruster, Tobermorites: their real structure and order-disorder (OD) character, Am. Mineral. 84 (1999) 1613-1621, https://doi. org /10.2138/am-1999-1015.

[64] E. Bonaccorsi, S. Merlino, A.R. Kampf, The crystal structure of tobermorite $14 \AA$ (plombierite), a C-S-H phase, J. Am. Ceram. Soc. 88 (2005) 505-512, https://doi. org/10.1111/j.1551-2916.2005.00116.x.

[65] I.G. Richardson, The calcium silicate hydrates, Cem. Concr. Res. 38 (2008) 137-158, https://doi.org/10.1016/j.cemconres.2007.11.005.

[66] F. Brunet, P. Bertani, T. Charpentier, A. Nonat, J. Virlet, Application of $29 \mathrm{Si}$ homonuclear and $1 \mathrm{H}-29 \mathrm{Si}$ heteronuclear NMR correlation to structural studies of calcium silicate hydrates, J. Phys. Chem. B 108 (2004) 15494-15502, https:// doi.org/10.1021/jp031174g.

[67] C. Biagioni, S. Merlino, E. Bonaccorsi, The tobermorite supergroup: a new nomenclature, Mineral. Mag. 79 (2015) 485-495, https://doi.org/10.1180, minmag.2015.079.2.22.

[68] F. Brunet, T. Charpentier, C.N. Chao, H. Peycelon, A. Nonat, Characterization by solid-state NMR and selective dissolution techniques of anhydrous and hydrated CEM V cement pastes, Cem. Concr. Res. 40 (2010) 208-219, https://doi.org/ 10.1016/j.cemconres.2009.10.005

[69] H. Hornain, G. Arliguie, GranDuBé - Grandeurs associées à la durabilité des bétons (in French), Presses des Ponts et Chaussées, 2007.

[70] J. Sercombe, R. Vidal, C. Gallé, F. Adenot, Experimental study of gas diffusion in cement paste, Cem. Concr. Res. 37 (2007) 579-588, https://doi.org/10.1016/j. cemconres.2006.12.003.

[71] C. Boher, F. Frizon, S. Lorente, F. Bart, Influence of the pore network on hydrogen diffusion through blended cement pastes, Cem. Concr. Compos. 37 (2013) 30-36, https://doi.org/10.1016/j.cemconcomp.2012.12.009.

[72] J. Crank, The Mathematics of Diffusion, 2nd ed., Clarendon Press, Oxford, 1975 https://doi.org/10.1016/0306-4549(77)90072-X.

[73] V.G. Papadakis, C.G. Vayenas, M.N. Fardis, Fundamental modeling and experimental investigation of concrete carbonation, ACI Mater. J. 88 (1991) 363-373.

[74] V.G. Papadakis, M.N. Fardis, C.G. Vayenas, Effect of composition, environmental factors and cement-lime mortar coating on concrete carbonation, Mater. Struct. 25 (1992) 293-304.

[75] Z. Šauman, Carbonization of porous concrete and its main binding components, Cem. Concr. Res. 1 (1971) 645-662.

[76] K. Mohan, H.F.W. Taylor, Analytical electron microscopy of cement pastes: IV, B-dicalcium silicate pastes, J. Am. Ceram. Soc. 64 (1981) 717-719, https://doi. org/10.1111/j.1151-2916.1981.tb15893.x.

[77] A. Nonat, The structure and stoichiometry of C-S-H, Cem. Concr. Res. 34 (2004) 1521-1528, https://doi.org/10.1016/j.cemconres.2004.04.035.

[78] L. Black, C. Breen, J. Yarwood, K. Garbev, P. Stemmermann, B. Gasharova, Structural features of C-S-H(I) and its carbonation in air-a Raman spectroscopic study. Part II: carbonated phases, J. Am. Ceram. Soc. 90 (2007) 908-917, https:// doi.org/10.1111/j.1551-2916.2006.01429.x.

[79] T. Ogino, T. Suzuki, K. Sawada, The formation and transformation mechanism of calcium carbonate in water, Geochim. Cosmochim. Acta 51 (1987) 2757-2767.

[80] J. Kawano, N. Shimobayashi, A. Miyake, M. Kitamura, Precipitation diagram of calcium carbonate polymorphs: its construction and significance, J. Phys. Condens. Matter 21 (2009) 425102, https://doi.org/10.1088/0953-8984/21/42/ 425102.

[81] M. Kitamura, Strategy for control of crystallization of polymorphs, CrystEngComm. 11 (2009) 949-964, https://doi.org/10.1039/b809332f.

[82] Y.S. Han, G. Hadiko, M. Fuji, M. Takahashi, Crystallization and transformation of vaterite at controlled pH, J. Cryst. Growth 289 (2006) 269-274, https://doi.org/ 10.1016/j.jcrysgro.2005.11.011.

[83] L. Fernández-Díaz, Á. Fernández-González, M. Prieto, The role of sulfate groups in controlling $\mathrm{CaCO}_{3}$ polymorphism, Geochim. Cosmochim. Acta 74 (2010) 6064-6076, https://doi.org/10.1016/j.gca.2010.08.010.

[84] M. Kellermeier, F. Glaab, R. Klein, E. Melero-García, W. Kunz, J.M. García-Ruiz, The effect of silica on polymorphic precipitation of calcium carbonate: an on-line 
energy-dispersive X-ray diffraction (EDXRD) study, Nanoscale. 5 (2013) 7054 https://doi.org/10.1039/c3nr00301a.

[85] Z. Zou, W.J.E.M. Habraken, G. Matveeva, A.C.S. Jensen, L. Bertinetti, M.A. Hood C.-Y. Sun, P.U.P.A. Gilbert, I. Polishchuk, B. Pokroy, J. Mahamid, Y. Politi, S. Weiner, P. Werner, S. Bette, R. Dinnebier, U. Kolb, E. Zolotoyabko, P. Fratzl, A hydrated crystalline calcium carbonate phase: Calcium carbonate hemihydrate, Science (80-. ) 363 (2019) 396-400.

[86] H. Deng, S. Wang, X. Wang, C. Du, X. Shen, Y. Wang, F. Cui, Two competitive nucleation mechanisms of calcium carbonate biomineralization in response to surface functionality in low calcium ion concentration solution, Regen. Biomater. 2 (2015) 187-195, https://doi.org/10.1093/rb/rbv010.

[87] I.G. Richardson, G.W. Groves, Models for the composition and structure of calcium silicate hydrate (CSH) gel in hardened tricalcium silicate pastes, Cem. Concr. Res. 22 (1992) 1001-1010, https://doi.org/10.1016/0008-8846(92) 90030-Y.

[88] X. Cong, R. James Kirkpatrick, 170 and 29Si MAS NMR study of $\beta$-C2S hydration and the structure of calcium-silicate hydrates, Cem. Concr. Res. 23 (1993) 1065-1077, https://doi.org/10.1016/0008-8846(93)90166-7.

[89] X. Cong, R.J. Kirkpatrick, 29Si MAS NMR study of the structure of calcium silicate hydrate, Adv. Cem. Based Mater. 3 (1996) 144-156, https://doi.org/10.1016/ S1065-7355(96)90046-2.

[90] Y. He, L. Lu, L.J. Struble, J.L. Rapp, P. Mondal, S. Hu, Effect of calcium-silicon ratio on microstructure and nanostructure of calcium silicate hydrate synthesized by reaction of fumed silica and calcium oxide at room temperature, Mater. Struct. 47 (2013) 311-322, https://doi.org/10.1617/s11527-013-0062-0.

[91] M. Castellote, L. Fernandez, C. Andrade, C. Alonso, Chemical changes and phase analysis of OPC pastes carbonated at different $\mathrm{CO} 2$ concentrations, Mater. Struct. 42 (2009) 515-525, https://doi.org/10.1617/s11527-008-9399-1.

[92] S. Goto, K. Suenaga, T. Kado, Calcium silicate carbonation products, J. Am. Ceram. Soc. 78 (1995) 2867-2872.

[93] G. Villain, G. Platret, Two experimental methods to determine carbonation profiles in concrete, ACI Mater. J. 103 (2006) 265-271.

[94] S.E. Pihlajavaara, Some results of the effect of carbonation on the porosity and pore size distribution of cement paste, Mater. Struct. 1 (1968) 521-527, https:// doi.org/10.1007/BF02473640.

[95] V.T. Ngala, C.L. Page, Effects of carbonation on pore structure and diffusional properties of hydrated cement pastes, Cem. Concr. Res. 27 (1997) 995-1007.

[96] P.A. Claisse, H. El-Sayad, I.G. Shaaban, Permeability and pore volume of carbonated concrete, ACI Mater. J. 96 (1999) 378-381.

[97] A. Morandeau, M. Thiéry, P. Dangla, Investigation of the carbonation mechanism of $\mathrm{CH}$ and $\mathrm{C}-\mathrm{S}-\mathrm{H}$ in terms of kinetics, microstructure changes and moisture properties, Cem. Concr. Res. 56 (2014) 153-170, https://doi.org/10.1016/j. cemconres.2013.11.015.

[98] A.J. Katz, A.H. Thompson, Quantitative prediction of permeability in porous rock, Phys. Rev. B 34 (1986) 8179-8181.

[99] A.S. El-Dieb, R.D. Hooton, Evaluation of the Katz-Thompson model for estimating the water permeability of cement-based materials from mercury intrusion porosimetry data, Cem. Concr. Res. 24 (1994) 443-455.

[100] V. Dutzer, W. Dridi, S. Poyet, P. Le Bescop, X. Bourbon, The link between gas diffusion and carbonation in hardened cement pastes, Cem. Concr. Res. 123 (2019) 105795, https://doi.org/10.1016/j.cemconres.2019.105795.

[101] P.H.R.R. Borges, N.B. Milestone, J.O. Costa, C.J. Lynsdale, T.H. Panzera, A. L. Christophoro, Carbonation durability of blended cement pastes used for waste encapsulation, Mater. Struct. 45 (2012) 663-678, https://doi.org/10.1617/ s11527-011-9788-8.

[102] A. Leemann, F. Moro, Carbonation of concrete: the role of $\mathrm{CO}_{2}$ concentration, relative humidity and $\mathrm{CO}_{2}$ buffer capacity, Mater. Struct. 50 (2017) 30, https:// doi.org/10.1617/s11527-016-0917-2.

[103] J.L. Branch, D.S. Kosson, A.C. Garrabrants, P.J. He, The impact of carbonation on the microstructure and solubility of major constituents in microconcrete materials with varying alkalinities due to fly ash replacement of ordinary Portland cement,
Cem. Concr. Res. 89 (2016) 297-309, https://doi.org/10.1016/j.

cemconres.2016.08.019.

[104] A. Leemann, P. Nygaard, J. Kaufmann, R. Loser, Relation between carbonation resistance, mix design and exposure of mortar and concrete, Cem. Concr. Compos. 62 (2015) 33-43, https://doi.org/10.1016/j.cemconcomp.2015.04.020.

[105] V. Shah, S. Bishnoi, Carbonation resistance of cements containing supplementary cementitious materials and its relation to various parameters of concrete, Constr. Build. Mater. 178 (2018) 219-232, https://doi.org/10.1016/j. conbuildmat.2018.05.162.

[106] S. Mindess, J.F. Young, F.V. Lawrence, Creep and drying shrinkage of calcium silicate pastes I. Specimen preparation and mechanical properties, Cem. Concr. Res. 8 (1978) 591-600.

[107] J.J. Chen, J.J. Thomas, H.M. Jennings, Decalcification shrinkage of cement paste, Cem. Concr. Res. 36 (2006) 801-809, https://doi.org/10.1016/j. cemconres.2005.11.003.

[108] A. Morandeau, M. Thiéry, P. Dangla, Impact of accelerated carbonation on OPC cement paste blended with fly ash, Cem. Concr. Res. 67 (2015) 226-236, https:// doi.org/10.1016/j.cemconres.2014.10.003.

[109] V. Shah, K. Scrivener, B. Bhattacharjee, S. Bishnoi, Changes in microstructure characteristics of cement paste on carbonation, Cem. Concr. Res. 109 (2018) 184-197, https://doi.org/10.1016/j.cemconres.2018.04.016.

[110] S.T. Pham, W. Prince, The carbonation of calcium-silicate-hydrate C-S-H in cement mortar studied using thermal analysis and gas pycnometer: determination of the quantity of calcium carbonate produced and the increase in molar volume, Adv. Mater. Res. 931-932 (2014) 411-415.

[111] R.J. Millington, J.P. Quirk, Permeability of porous solids, Trans. Faraday Soc. 57 (1961) 1200-1207, https://doi.org/10.1039/TF9615701200.

[112] M. Xie, K.U. Mayer, F. Claret, P.A. Diederik, J. Carl, C. Chiaberge, J. Simunek, Implementation and evaluation of permeability-porosity and tortuosity-porosity relationships linked to mineral dissolution-precipitation, Comput. Geosci. 19 (2014) 655-671, https://doi.org/10.1007/s10596-014-9458-3.

[113] J. Hommel, H. Class, E. Coltman, Porosity - permeability relations for evolving pore space: a review with a focus on (bio-)geochemically altered porous media, Transp. Porous Media 124 (2018) 589-629, https://doi.org/10.1007/s11242018-1086-2.

[114] T.C. Powers, A hypothesis on carbonation shrinkage, J. PCA Res. Dev. Lab. 4 (1962) 40-50.

[115] J. Xiao, J. Li, B. Zhu, Z. Fan, Experimental study on strength and ductility of carbonated concrete elements, Constr. Build. Mater. 16 (2002) 187-192, https:// doi.org/10.1016/S0950-0618(01)00034-4.

[116] J.J. Chang, W. Yeih, R. Huang, J.M. Chi, Mechanical properties of carbonated concrete, J. Chin. Inst. Eng. 26 (2003) 513-522.

[117] J. Jerga, Physico-mechanical properties of carbonated concrete, Constr. Build. Mater. 18 (2004) 645-652, https://doi.org/10.1016/j.conbuildmat.2004.04.029.

[118] C.F. Chang, J.W. Chen, Strength and elastic modulus of carbonated concrete, ACI Mater. J. 102 (2005) 315-321, https://doi.org/10.14359/14710.

[119] C. Carde, R. François, Effect of the leaching of calcium hydroxide from cement paste on mechanical and physical properties, Cem. Concr. Res. 27 (1997) 539-550.

[120] C. Le Bellego, B. Gérard, G. Pijaudier-Cabot, Chemo-mechanical effects in mortar beams subjected to water hydrolysis, J. Eng. Mech. 126 (2000) 266-272.

[121] U. Schneider, S.W. Chen, Deterioration of high-performance concrete subjected to attack by the combination of ammonium nitrate solution and flexure stress, Cem. Concr. Res. 35 (2005) 1705-1713, https://doi.org/10.1016/j. cemconres.2004.11.011.

[122] V.H. Nguyen, H. Colina, J.M. Torrenti, C. Boulay, B. Nedjar, Chemo-mechanical coupling behaviour of leached concrete. Part I: experimental results, Nucl. Eng. Des. 237 (2007) 2083-2089, https://doi.org/10.1016/j.nucengdes.2007.02.013.

[123] I. Yurtdas, S.Y. Xie, N. Burlion, J.F. Shao, J. Saint-Marc, A. Garnier, Influence of chemical degradation on mechanical behavior of a petroleum cement paste, Cem. Concr. Res. 41 (2011) 412-421, https://doi.org/10.1016/j. cemconres.2011.01.008. 